Postprint: Ghanem, C., Lawson, T. R., Pankofer, S., Maragkos, M. \& Kollar, I. (2017). The diffusion of evidence-based practice: reviewing the evidence-based practice networks in the United States and German-Speaking Countries. Journal of Evidence-Informed Social Work, 14(2), 86-118. DOI: 10.1080/23761407.2017.1298074

The Diffusion of Evidence-Based Practice: Reviewing the Evidence-Based Practice Networks in the United States and German-Speaking Countries

Christian Ghanem, ${ }^{\mathrm{a}, \mathrm{b}}$, Thomas R. Lawson ${ }^{\mathrm{c}}$, Sabine Pankofer ${ }^{\mathrm{b}}$, Markos Maragkos ${ }^{\mathrm{d}}$, and Ingo

$$
\text { Kollar }^{\mathrm{a}, \mathrm{e}}
$$

${ }^{a}$ Munich Center of the Learning Sciences, Ludwig-Maximilians-Universität München, Munich, Germany;

${ }^{\mathrm{b}}$ Department of Social Work, Katholische Stiftungsfachhochschule München, Munich, Germany;

${ }^{c}$ Kent School of Social Work, University of Louisville, Louisville, Kentucky, USA;

${ }^{\mathrm{d}}$ Arbeitsgemeinschaft für Verhaltensmodifikation München, Munich, Germany;

${ }^{\mathrm{e}}$ Educational Psychology, University of Augsburg, Germany 


\begin{abstract}
Evidence-based practice (EBP) has had a major influence on U.S. social work while it has rarely been adapted in German-speaking countries. This study investigates how knowledge about EBP is diffused within and across geographical contexts. Network analysis methods reveals different diffusion patterns and provide reasons for these differences. For example, the U.S. discourse is self-contained and based on a more homogeneous knowledge base, while the German discourse is more heterogeneous and focuses on a notion of reflexive professionalism. The different conceptual influences within the U.S. and German discourses are discussed in light of future directions of disciplinary social work.
\end{abstract}

\title{
Keywords
}

Evidence-based practice; review; science mapping; citation analysis; network analysis; knowledge diffusion 


\section{Evidence-based Practice in Social Work}

The question of whether social work can be considered a science has led to thoughtprovoking debates among scholars (Brekke, 2012; Briar-Lawson, 2012; Longhofer \& Floersch, 2012; Marsh, 2012; Shaw, 2014, 2016; Sommerfeld, 2014). Brekke (2012) suggested that social work is poised to define itself as a science because of its research productivity. His argument focused on social work in the United States. Perron and colleagues (2016) provided evidence of the vast growth of social work research worldwide, as indicated by the ongoing founding of new journals in the discipline. The growth of scientifically generated knowledge and the claim that social work is conceived as a profession (Abbott, 1988; Sommerfeld, 2014) —although this professional status is unclear or even rejected by some scholars (see Staub-Bernasconi, 2013, for a summary about the corresponding discussion in German-speaking countries) — has led to increasing attention on the intersection of scientific knowledge and practice.

According to the analysis of Okpych and Yu (2014), the orientation towards scientifically generated empirical knowledge is a fundamental part of the current paradigm in social work practice. Their analysis identified the empirical clinical practice movement (cf. Reid, 1994) as the starting point of a new paradigm, whereas the model of evidence-based practice (EBP) has carried the transition forward from an authority-based to an empirically based paradigm. Other scholars have even labeled EBP itself as a paradigm (Gambrill, 2006, p. 339; Howard, Himle, Jenson, \& Vaughn, 2009, p. 263; Howard, McMillen, \& Pollio, 2003, p. 234).

Initially founded in medicine (Sackett, Rosenberg, Gray, Haynes, \& Richardson, 1996) and transferred to social work (Gambrill, 1999), EBP describes a five-step process to address a practical problem: (1) formulating an answerable question relevant to the given problem, (2) identifying information needed to solve the problem, (3) critically appraising this information, (4) applying the results to the situation and triangulating scientific knowledge 
with the given circumstances including one's own experience and the client's values and preferences, and (5) evaluating the outcome. Although this definition of EBP, often described as a bottom-up approach (Okpych \& Yu, 2014, p. 25), has hardly been unchallenged, the individual understanding of EBP varies (Rubin \& Parrish, 2006). This confusion might be at least partly caused by interpreting the term EBP as advocating research-supported interventions (cf. Downing, 1996; Thyer, 2015), which is often referred to as a top-down approach (Gambrill, 1999).

EBP has been extensively discussed, especially in the United States, where the Journal of Evidence-Informed Social Work (formerly the Journal of Evidence-Based Social Work) was founded. The historical analysis of social work practice by Okpych and Yu (2014) also focused on the developments in the United States. Hence, their analysis did not answer whether the major influence of EBP on social work practice is evident in other geographical contexts as well. EBP has also had a crucial influence on other countries such as Australia (Barber \& Dunston, 2004), England (e.g., Sheldon \& Chilvers, 2004), and Sweden (Sundell, Soydan, Tengvald, \& Anttila, 2010). For instance, a citation analysis revealed evidence of the influence of EBP beyond the United States (Hodge, Lacasse, \& Benson, 2012). According to that study, the British Journal of Social Work article by British author Stephen Webb (2001), which critically reflected on EBP, has received more attention than any other article published in a journal dedicated to social work (Hodge et al., 2012).

Although EBP has provoked a strong response in social work, geographical differences seem to exist. In Germany, for instance, the influence of EBP does not seem to fit the historical analysis of Okpych and Yu (2014). Students of social work in German universities are rarely taught about EBP, and many of them have never heard anything about it. Although this claim is only based on our own experiential evidence, there seems to be a crucial difference in the extent to which EBP has been adapted in social work between the founding country (the United States) and Germany. There have been attempts to elaborate on 
the reasons for the different adaptations of EBP (James, 2016; Otto, 2007; Sommerfeld, 2016). These outlined differences imply the first hypothesis:

H1: The core of the EBP debate is located in the United States.

The main goal of this research is to investigate whether differences exist in the intellectual structure of the EBP discourses between two geographical contexts and why the same knowledge corpus (underlying EBP) seems to be adapted differently. Previous work might provide explanations for different adaptations of EBP in the German and U.S. discourses. For example, a recent study by Kreisberg and Marsh (2016) revealed that disciplinary social work in the United States mainly focuses on research, whereas European social work focuses on theory. Since EBP might inherently apply a research focus and neglect theory, even though considering theory is not excluded (Thyer, 2013), it might have provoked a strong response in the United States and not in German-speaking countries.

H2: The EBP discourse in the United States differs from the German discourse in terms of the focus of the publications (theory focus in German speaking countries versus empirical focus in the United States).

\section{Knowledge diffusion in scientific disciplines}

This study aims to analyze the knowledge construction processes around EBP and how the underlying knowledge has diffused in the United States and in German-speaking countries. This section introduces our theoretical perspective, as well as the hypotheses derived from it, followed by the methodological approach applied to investigate knowledge diffusion processes within the social work discipline. 


\section{Theoretical background}

In the last decades, the importance of knowledge, innovations, and research has continuously grown. This development is conceptualized under the term "knowledge society" (United Nations Educational, Scientific, and Cultural Organization, 2005; Välimaa \& Hoffman, 2008). There is a strong political movement aiming for more inclusive and accessible knowledge for all citizens (United Nations Educational, Scientific, and Cultural Organization, 2014).

Scientific disciplines are considered central to a transition to a knowledge society and even seen as "the premier knowledge institution[s] throughout the world" (Knorr-Cetina, 1999, p.

1). Scientific disciplines ideally generate new knowledge about phenomena based on existing scholarly work. Knowledge accumulation is often proposed as ideal for scientific disciplines (Bird, 2007). However, accumulation cannot be understood as a linear process of summing up different pieces of knowledge (Abbott, 2006). Although knowledge diffusion can be defined as "the adaptations and applications of knowledge documented in scientific publications and patents" (Chen \& Hicks, 2004, p. 199), it is not assumed to be a technical, linear process, as might be implied by this definition. The local standards and conventions influence the way knowledge is adapted (Crane, 1972; Knorr-Cetina, 1981; Rogers, 2003), which might lead to specific knowledge constructions and specific local accumulations (Abbott, 2001). This claim is supported by network analysis results showing a certain degree of disunification of social science disciplines hindering the dissemination of knowledge (Yan, 2014). Accordingly, it would not be surprising if scientific communities of different geographical contexts adapt EBP differently, especially if the underlying knowledge diffuses and circulates differently within certain entities, for instance, scientific communities.

Diffusion is a social process and a specific kind of communication (Rogers, 2003). Liu and Rousseau (2010) differentiated two ways of knowledge diffusion within scientific disciplines: diffusion by publications and diffusion by citations. Diffusion by publications "originates from an internal mechanism by which the group itself expands its borders" (Liu \& 
Rousseau, 2010, p. 340). However, publications alone are not sufficient to spread knowledge. To influence the scientific discourse, they need to be referred to by others; this is indicated by whether and how often the publications receive citations. The ways of diffusion, by publications and by citations, can be seen as complementary. The hypotheses stated earlier, as well as the next hypotheses, focus on diffusion by publications. They are based on the observation that EBP has not been adapted in Germany (James, 2016) but has had a huge influence on U.S. social work (Okpych \& Yu, 2014).

H3: EBP has been diffused through publications in the United States.

H4: EBP has not been diffused through publications in German-speaking countries.

Diffusion by publications is a process in which the knowledge sender (author) publishes scientifically generated knowledge that enables others (knowledge recipient) to adapt the knowledge. The publication itself is a crucial element of diffusion processes which serves as communication channel (Rogers, 2003). The diffusion process is most effective when the publications are freely available online (Davis, 2011). Although many journal publications are not freely available and many scholars have no access to specific online journals (depending on the university they are employed in), one can assume that publishing in journals compared with other publication formats, for instance, monographs, comes with a higher chance of others receiving the published knowledge. Furthermore, in most scientific disciplines, the double-blind peer-review process — which is primarily done for journal publications - might also be one reason for the scientific community to acknowledge and adopt journal publications more than other publication formats. An increase of journal publications within a scientific discipline might, therefore, go along with a more homogeneous knowledge base on which knowledge can freely flow and be exchanged. A 
relatively limited knowledge exchange about EBP might, therefore, be one reason why EBP has rarely been discussed in German-speaking countries.

H5: The U.S. EBP discourse differs from the German EBP discourse in terms of the publication format (journal publications vs. other publication formats).

Besides the mechanism of knowledge diffusion through publishing, a second kind of diffusion is indicated by citations (Liu \& Rousseau, 2010). Citations can be seen as a valid indicator that disciplinary knowledge flows from a sender to a recipient (Yan, 2014). Citations also indicate a semantic relationship between the citing and the cited publication (Garfield, 1994a). Despite some counterevidence to this assumption (Greenberg, 2009; Harter, Nisonger, \& Weng, 1993), it is widely accepted that citation patterns can reveal intellectual commonalities or the intellectual foundation that the field is based on. They also indicate scientific communication or structural ties (Cobo, López-Herrera, Herrera-Viedma, \& Herrera, 2011; Cronin, 1994; Gmür, 2003; Peters, Braam, \& van Raan, 1995). Accordingly, citation analyses can identify patterns of social structure, communication, and knowledge flows within scientific communities (Crane, 1972). Regarding our research focus and the assumption of differences between the EBP discourse in the United States and in Germanspeaking countries, particularly between "epistemic cultures" (Knorr-Cetina, 1999), this would mean that EBP publications of these two discourses differ in their intellectual structure, as indicated by different citations.

H6: The EBP discourses in the United States and in German-speaking countries are influenced by different schools of thought. 
Knowledge diffusion is determined by specific citation patterns of actors within national contexts (Jaffe \& Trajtenberg, 1999). Shaw (2014, p. 521) claimed that this also applies to social work and that scholars apply an "inward gaze," mainly referring to scholarly work from their own countries. Therefore, the next hypotheses are based on the assumption that scientific disciplines as well as discourses within certain disciplines are self-contained (Yan, 2014).

H7: The EBP discourse network is self-contained in the United States.

H8: The EBP discourse network is self-contained in German-speaking countries.

The consideration of citations as a proxy for knowledge flow allows for the consideration of scientific disciplines as networks. The underlying presumption is that a scientific network consists of different actors or nodes (e.g., publications), which are interconnected with other actors or nodes by ties or edges (e.g., citations). Various network concepts are applicable to investigating scientific networks (Borgatti, Everett, \& Johnson, 2013). One of the most often applied concepts is centrality, which was introduced by Bavelas (1950). He investigated how structural properties of actors within groups influence the effectiveness of their communication and group performance. In general, centrality can be seen as an indicator of social capital, which provides central actors with opportunities to influence others or receive (e.g., knowledge) flows (Borgatti et al., 2013, p. 164). The more central the position of an actor in a network, the higher its structural importance. Applied to our research focus, a highly central EBP publication can be perceived as a proxy for the opportunity to forward knowledge (Haythornthwaite, 1996). Different highly central publications between two networks might therefore lead to different conceptual embeddings of the scientific discourses, which would mean that the initial knowledge about EBP is merged with other knowledge claims embedded in other publications. 
H9: The EBP discourses in the United States and in German-speaking countries differ in their conceptual embedding.

The degree of knowledge flow is determined by the individual (Szulanski, 1996) and structural properties of a network (Yan, 2014). For instance, referring to Crane's (1972) concept of invisible colleges, Abbott $(2001,2006)$ claimed that these more or less dense networks tend to share a set of conventional assumptions. If we assume that these assumptions can be embedded in scientific publications, then a network in which a certain piece of knowledge can be diffused has to show a certain degree of homogeneity. Hence, this presumption might serve as an explanation for why EBP seems to be widely adapted in the United States and rarely adapted in German-speaking countries.

H10: The EBP discourse in the United States is more homogeneous than the EBP discourse in German-speaking countries.

\section{Methodological approaches to investigating knowledge diffusion in scientific disciplines}

To test our hypotheses, we used network and citation analyses, which will be discussed in the following sections.

\section{Citation analyses}

The rapid change in information storage and the development of software tools to analyze disciplinary information (often referred to as scientometrics) have led to increasing efforts to systematically investigate scientific communities, including social work (Perron et al., 2016). Scientometrics is a discipline dedicated to the "quantitative study of science, communication in science, and science policy" (Hess, 1997, cited by Leydesdorff \& Milojevic, 2015). Largely influenced by the work of Garfield (e.g., 1972) and de Solla Price (e.g., 1965), scientometrics 
has a long tradition in the analysis of citation patterns. Citation analysis has become a major method to evaluate scholarly impact in diverse disciplines. The most widespread measurements are the journal impact factor (Garfield, 1972) and the newer h-index, which is applicable on an author level (Hirsch, 2005). Despite the criticism of citation analysis for evaluating the performance of individual work (e.g., Garfield, 1998), it is commonly used as a proxy to evaluate scholarly work. This is also true for social work. In addition to the journal impact factor or related citation indexing methods applied to social work journals, citation analysis has also been used by individual scholars to systematically investigate the discipline of social work (e.g., Barner, Holosko, \& Thyer, 2014; Bloom \& Klein, 1995; Bush, Epstein, \& Sainz, 1997; Hodge et al., 2012; Holden, Rosenberg, Barker, \& Lioi, 2009; Ligon, Thyer, \& Cobb, 2012; Lindsey \& Kirk, 1992).

For citation analysis, different units of analysis can be applied. Citation data can be aggregated on the level of journals (e.g., Holden et al., 2009) or faculty (Barner et al., 2014). However, the most used units of analysis are authors or documents (Gmür, 2003). In this study, we focus on documents, particularly on scientific publications. Citation data can be investigated through various methods (Boyack \& Klavans, 2010). The simplest form of citation analysis is the use of direct citations, that is, to count the number of citations that a specific publication, author, or journal has received. Citations can also be analyzed by considering the context in which they appear: bibliographic coupling or co-citations (Garfield, 2001). Bibliographic coupling analyzes the occurrence of the same citation in different publications. Two publications are coupled if at least one common reference appears in their reference lists. Through this method, one can investigate similar citation patterns of different authors. While bibliographic coupling searches for associations between citing publications or authors, co-citation analysis investigates associations between cited articles or authors. The number of co-citations of two publications (a pair of publications appear in one reference list) indicates the closeness of the co-cited documents or authors as perceived by the investigated 
discipline (White \& Griffith, 1981). Co-citations provide promising data to identify various "conversation topic[s] within the discipline" (Healy, 2013, para. 5). Hence, co-citation patterns can reveal the conceptual influence on the construction of EBP and related topics.

\section{Science mapping}

Citation analysis methods have often been combined with network analysis. This combination can be found among different methodological concepts, such as "science mapping" (Cobo et al., 2011), "scientography” (Garfield, 1994b), "bibliometric mapping” (Noyons, 1999), and “mapping knowledge domains” (Börner, Chen, \& Boyack, 2003; Shiffrin \& Borner, 2004). Throughout this study, we refer to science mapping when talking about network analysis based on bibliographic data (even though it is not restricted to bibliographic data, see Cobo et al., 2011). Science mapping is seen as a useful tool to "describe how specific disciplines, scientific domains, or research fields are conceptually, intellectually, and socially structured" (Cobo et al., 2011, p. 1382). The network of co-citation data, for instance, can be visualized by considering each publication as a node and each appearance with another publication within a reference list as an edge. The result would be a weighted network in which each edge has a specific weight according to the frequency a specific pair of publications is cited together within one other publication. Network analysis methods allow to map and analyze the resulting network. The spatial representation of the data can enhance the analysis process by depicting physical proximity and relative locations of individual articles or authors (Small, 1999). Science mapping techniques have also been used in social work (Baker, 1992; Martínez, Cobo, Herrera, \& Herrera-Viedma, 2015). A recent study by Martínez and colleagues (2015), for instance, combined the h-index data with a co-word analysis (which and how often specific words occur together within the unit of analysis, e.g., in one article) to depict thematic networks about the evolution of the social work discipline. Network analysis includes a large number of different analytical approaches, and their description is far beyond 
the scope of this article (for an elaborated introduction, see Scott, 2013). This article will focus on two basic network concepts: density and network centrality. Density describes "the general level of linkage among the points in a graph" (Scott, 2013, p. 69) and represents the ratio of actual edges between nodes to the maximum possible number of edges. The more nodes, for instance, scientific publications, are connected to each other, the denser the network will be. Applied to our research interest, a low density within a co-citation network would indicate that many of the citations appear rarely or only once within the reference lists of EBP publications. A high density would be associated with a certain degree of homogeneity of knowledge that is referred to by EBP writings. The second concept we want to introduce is network centrality. When investigating a scientific field, the use of network centrality is complementary to citation analysis methods (Yan \& Ding, 2009). There are different ways of conceptualizing and measuring centrality (Borgatti, 2005). Perhaps the most widespread centrality measures are closeness centrality, betweenness centrality, and degree centrality (Valente, Coronges, Lakon, \& Costenbader, 2008). This study is based on degree centrality and a variation of it called eigenvector centrality. These centrality measures are appropriate for investigating knowledge flows (Borgatti, 2005). Degree and eigenvector centrality can be subsumed under degree-like measures because they focus on the direct surroundings of a node by analyzing the direct edges with other nodes (Borgatti \& Everett, 2006).

Degree centrality is measured by the number of edges a specific node has with other nodes (Borgatti et al., 2013, p. 165). Hence, it implies how well connected a node is to its surroundings and indicates the likelihood of being able to influence and becoming influenced by other nodes. In a direct network based on citations, in which each node represents either a cited publication or a citing publication (two-mode network), a node has a high degree centrality when it receives relatively many citations. A high degree centrality in a co-citation network means that a publication is often cited together with other specific publications. This 
connectedness implies that the scientific knowledge of these pairs of publications flows to one another and is merged within another publication. Therefore, a publication with a high degree centrality indicates a high chance of having influence on the scientific discourse.

Eigenvector centrality takes into consideration how well connected the node connected to the analyzed node is (Bonacich, 2007). It can be seen as a variation of degree centrality in which the adjacent node is weighted by its centrality (Borgatti et al., 2013, p. 168). In contrast to a simple degree centrality, this can lead to a low centrality of a highly connected node if this node is connected to only low central nodes. Accordingly, a node can have a high eigenvector centrality if it is connected to only a few other nodes and these adjacent nodes have a high centrality. Hence, in a co-citation network, a low-cited publication can also highly influence the scientific discourse if it is often cited together with one central publication. For our analysis of EBP networks, this means that a rarely cited publication has a high "risk" (Borgatti, 2005, p. 61) of influencing the discourse if its citations occur together with the first article about EBP in social work by Gambrill (1999), which is assumed to be a central one within the discourse.

\section{Method}

\section{Literature search and data preparation}

A comprehensive literature search was conducted to identify publications relevant to the research questions. Since we expected to find most of the publications of German authors in printed books, a search strategy that went beyond the common databases was necessary. Therefore, the search started with the most common generic and specific databases and was stopped to search other databases once no additional publications could be identified (cf. Blanke, Bandemer, Nullmeier, \& Wewer, 2005, p. 100). We retrieved records from the following databases: Social Service Abstracts, Social Citation Index, Education Resources Information Center, PsycINFO, SocIndex, Scopus, ProQuest Social Sciences, Sociological 
Abstracts, Wirtschaft and Soziales, Psyndex, Sozialwissenschaftliches Fachportal, Bielefeld Academic Search Engine, FIS Bildung, Fachportal Pädagogik, PubPsych, and DZI Solit. We also searched the databases of Social Care Institute for Excellence, the Journal of EvidenceInformed Practice, Google Scholar, and Google Books. In all these databases, we searched for publications fulfilling the following inclusion criteria:

- Title includes "evidence-based practice" OR “evidence-informed practice" OR “evidence-based social work" OR “evidence-informed social work” AND "social work" included in keywords OR journal title OR subject terms OR title

- Published from 1996 to 2015

- Language: German OR English

This search strategy was complemented by a hand search, which proved to be relevant especially for German publications. A snowball search (Petticrew \& Roberts, 2006) was applied until we could no longer find new publications. We eventually identified 961 publications. After excluding 211 duplicates, we ended up with 750 publications for further screening (see Figure 1). Through this screening, we identified 18 publications that have been published more than once. For instance, sometimes a journal article was also found as a book chapter. We only excluded these double publications if they were $100 \%$ identical. Due to this clear operationalization, an interrater reliability check was not necessary. The same is true for the exclusion of book reviews $(n=86)$ and the exclusion of publications from other disciplines $(\mathrm{n}=27)$. If the term "social work" was not found within the publication, it was not considered part of the disciplinary social work discourse. One record was excluded because the existence of the publication could not be verified by a hand search.

We recognized that many of the remaining publications did not seem to report any relevant information about EBP itself but rather presented research-supported interventions that do not reflect the conceptual background of EBP. Therefore, we decided on two more exclusion criteria: First, we excluded those publications in which the inclusion terms 
regarding the title did not appear in a row $(\mathrm{n}=92)$. We inferred this criterion from the finding that many titles had a structure like "Therapy X: An evidence-based approach for social work practice" (fixed terms such as "evidence-based policy and practice" were not excluded). Second, we excluded publications using the plural "evidence-based/-informed practices" in the title. Those publications usually focus on research-supported interventions and are, therefore, not relevant to our research questions. After these exclusion processes, the result was 482 publications (worldwide).

\section{INSERT FIGURE 1 ABOUT HERE}

Since many of the stated hypotheses focus on a comparison of the EBP discourses in the United States and in German-speaking countries, we had to identify the corresponding publications from the remaining sample. Therefore, each publication was coded by the affiliation of the first author. For instance, a publication written by a first author from the United States was considered part of the disciplinary discourse in the United States. Germanspeaking countries included Germany, Austria, and Switzerland. One publication from South Tyrol in Italy (which is mainly a German-speaking region) was also classified as originating from a German-speaking country. From the identified German and U.S. samples, we had to exclude records of edited book authorships, which led to 302 publications written by U.S. authors and 33 written by German-speaking authors.

A further screening of the German and U.S. samples still showed that many of the remaining publications did not provide any definition of or reflections on EBP. Hence, another exclusion criterion was applied, namely, the exclusion of non-conceptual contributions, as indicated by publications reporting on research findings or practice reports. Two independent coders coded $50 \%$ of the publications $(n=166)$ based on three categories: 
mainly empirical (publications presenting primary data and systematic reviews), mainly conceptual (publications conceptually elaborating on EBP), and technical (publications presenting concrete practice projects, such as the presentation of a school of social work or the implementation of an intervention in a specific organization). The coding reached an appropriate interrater reliability with a Cohen's kappa value of 0.82 . The remaining conceptual EBP publications from the United States $(\mathrm{N}=209)$ and German-speaking countries $(\mathrm{N}=26)$ served as the basis for further analyses.

\section{Operationalization of variables}

Table 1 summarizes the operationalization of the other variables under study. The operationalization of the diffusion of EBP (H3 and H4) is based on Chen and Hick's (2004) argument that knowledge diffusion has occurred if the number of publications exponentially increases. For the comparison of the most central publications within both networks (H6-H9), we excluded the founding publications represented by Gambrill's article (1999), which transferred EBP from medicine to social work, aswell as Sackett and colleagues' (1996) article, which is often claimed to be the first work about evidence-based medicine (although it can be seen as a collaborative result of the Evidence-Based Medicine Working Group established in the early 1990s; cf. Evidence-BasedMedicineWorking Group, 1992). Besides these two publications, we also excluded the first textbook about evidence-based medicine (Sackett, Straus, Richardson, Rosenberg, \& Haynes, 1997, 2000). This book is considered the first publication to systematically summarize the origins and underlying concepts of evidencebased medicine (Gambrill, 2010). The rationale behind this exclusion is that most EBP publications refer to these articles and aim to investigate differences regarding the links between the initial EBP idea and other disciplinary knowledge. 


\section{Network construction}

The present study aims to examine, among other topics, which concrete intellectual ideas have had an influence on the EBP discourses. Therefore, for a small-grained analysis, scientific publications representing concrete ideas were used as the unit of analysis. We retrieved each reference from 26 German publications. To make the German and U.S. citations comparable, we took a random sample of 26 U.S. publications and retrieved the citations from this sample. Since our samples included many monographs and book chapters, it was not possible to process this data retrieval automatically (for most journal publications, it is possible to automatically retrieve the references from different databases, such as Web of Knowledge). Hence, we manually transferred the references $(\mathrm{N}=2,823)$ to Microsoft Excel and prepared a two-mode matrix with two dimensions: the citing documents and the cited documents (cf. Everett \& Borgatti, 2013). On the one hand, this matrix represents a directed network, which means that the knowledge from the cited document flows to the citing document. On the other hand, the resulting network is unvalued, since the matrix includes only ones and zeros (document A cites or does not cite document B). The resulting network was used to test H1H5.

Since we were also interested in the influence of the cited documents, we excluded the dimension of the citing documents and transformed the two-mode network into a one-mode network (through a specific feature provided by UCINET; cf. Borgatti, Everett, \& Freeman, 2002), which represents an undirected network. This matrix is called co-occurrence matrix (cf. Leydesdorff \& Vaughan, 2006) because both dimensions are equal and the values in the cells represent how often two documents co-occur within one citing document. Since the values can be greater than one, this kind ofmatrix represents a valued network. For instance, if 
document A co-occurs with document B four times, the edge between them has a weight of four.

Some scholars have suggested normalizing the data for science mapping techniques (Martínez et al., 2015). However, there are ambiguous standpoints on how to do so and whether co-occurrence matrices should be normalized (Leydesdorff, 2007; Leydesdorff \& Vaughan, 2006; Wallace, Gingras, \& Duhon, 2009; Waltman \& van Eck, 2007). To yield a more empirically valid picture, we decided to follow the suggestion by (Wallace et al., 2009) to use raw data. Normalization was not required because we did not apply advanced networking methods. The constructed co-citation networks consisted of 1,389 nodes with 126,092 edges for the U.S. sample and 833 nodes with 33,442 edges for the German sample. In terms of centrality measures, several different methods have been developed for weighted networks (Opsahl, Agneessens, \& Skvoretz, 2010). Although different measures often correlate with each other, they can be considered related but still distinct concepts (Valente et al., 2008). For instance, in the case of eigenvector centrality, if there are a few high-degree nodes connected to many low-degree ones, which we can expect in our citation data, then the result might differ from the results of other centrality measures (Bonacich, 2007). Therefore, different centrality measures are complementary to each other. Due to the underlying concepts introduced above (see "Science mapping"), we used eigenvector centrality and degree centrality. Degree centrality was calculated on weighted degrees, defined as the sum of each co-occurrence of a publication with another publication (Borgatti et al., 2013, p. 178f). These two measures can be applied to weighted networks without any significant modifications. To depict the network and to calculate and represent the centrality outcome, we used Gephi, a network visualization software (Bastian, Heymann,\&Jacomy, 2009). The graph drawingwas based on the algorithm of Fruchterman and Reingold (1991).

\section{Results}




\section{Diffusion of EBP by publications (RQ1)}

EBP publications worldwide (H1)

Hypothesis 1 states that the core of the EBP discourse(s) is located in the United States. Table 2 shows the distribution of EBP publications by country. Since German and English written publications were included, Germany and Switzerland had a relatively high number of publications. Most of the publications were written by authors from the United States, which verifies our hypothesis.

INSERT TABLE 2 ABOUT HERE

Empirical versus theory focus (H2)

Hypothesis 2 assumes differences between the U.S. discourse and the German-speaking discourse regarding the focus of the publications. It is assumed that the U.S. discourse have a stronger focus on empirical work while the German discourse applies a theory focus. Out of the 302 EBP publications from the United States, 85 (28.15\%) were identified as mainly empirical, eight (2.65\%) as technical, and 209 (69.2\%) as mainly conceptual. The German sample consisted of three (10.34\%) empirical and $26(89.66 \%)$ conceptual publications.

Although these results show that the U.S. discourse applies a stronger research focus, conceptual publications were the most common in both samples. A statistical comparison of the conceptual and empirical publications from both samples (technical publications were not considered for this analysis since it was not relevant to the hypothesis under study) confirmed a significant association between the country and the type of publication, $\chi^{2}(1)=4.59, \mathrm{p}<$ .05 . 


\section{Diffusion of EBP through publications (H3 and H4)}

Hypotheses 3 and 4 state that a process of EBP diffusion has happened in the United States but has been absent in German-speaking countries. To depict the dynamics of the publication patterns, the years of publication (of conceptual EBP publications) are compared in Figure 2. The figure shows that the discourse about EBP in the United States started to increase immediately after the article by Gambrill was published in 1999. The discourse reached its peak in 2008 with 32 publications and started to diminish afterwards. It should be noted, however, that the number of publications per year has increased since 2013. In the sample of German-speaking countries, the first article was published in 2005. The most publications per year, namely five, appeared in 2012. Overall, there are fewer publications per year from German-speaking countries, and there appears to be a consistent time lag of 1 to 3 years, with increases and decreases showing a similar pattern as the United States. Regarding the hypothesis that a diffusion of EBP has occurred in the United States, the results show that there have been two phases of diffusion, as indicated by the exponential growth of the number of publications between 1999 and 2004, as well as between 2005 and 2008. The absence of this growth in the German sample provides evidential support for $\mathrm{H} 4$.

\section{INSERT FIGURE 2 ABOUT HERE}

\section{Publication formats (H5)}

Table 3 depicts the publication formats of the identified conceptual EBP publications. It supports our hypotheses that conceptual knowledge about EBP is mainly spread through journal publications in the United States $(58.37 \%)$ and through other publication formats (chapters and monographs) in German-speaking countries (61.54\%). This difference barely missed statistical significance, $\chi 2(1)=3.72, p=.054$. Nineteen out of the 26 publications in 
the German sample are written in German. Moreover, the analysis identified two journals that seem to represent the main communication channel for EBP knowledge: Research on Social Work Practice and Journal of Evidence-Informed Social Work.

INSERT TABLE 3 ABOUT HERE

\section{Diffusion of EBP by citations (RQ2)}

\section{Influence of different schools of thought (H6)}

The next step in the analysis was to test the assumption that different schools of thought underlie the EBP discourses in the United States and in German-speaking countries. Table 4 provides an overview of publications frequently cited by the EBP publications under study. The 10 most cited EBP publications of U.S. authors include the canonical works about evidence-based medicine by Sackett and his colleagues (1996, 2000; Straus, Richardson, Glasziou, \& Haynes, 2005), as well as about EBP in social work by Gambrill $(1999,2013)$ and Gibbs (2003). Publications about practice guidelines have also influenced the U.S. discourse (Howard \& Jensen, 1999; Rosen \& Proctor, 2003).

Among the most cited publications within the German discourse network is one by McNeece and Thyer (2004) proposing a hierarchy of evidence. The article by Webb (2001) challenging the validity of EBP is also highly cited within the German sample, in addition to Pawson's (2002) work, which challenges the consideration of meta-analyses as the gold standard for EBP (cf. McNeece \& Thyer, 2004). Moreover, the works by Hüttemann (2006) and Otto and Ziegler (2006) are highly cited German publications critically appraising the underlying concepts of EBP, particularly the concrete application of EBP in German-speaking countries. Ideas of reflexive professionalism (Dewe \& Otto, 2012) or, more generally, a hermeneutic-oriented theory of professionalization (Oevermann, 1996) can also be found in 
these most cited publications. These findings support the claim that different scientific knowledge has influenced the German and U.S. discourses.

INSERT TABLE 4 ABOUT HERE

\section{Self-contained EBP networks (H7 and H8)}

Hypothesis 7 states that the majority of the most cited publications within the U.S. discourse network are written by authors from the United States. After excluding the founding papers (see "Operationalization of variables"), the U.S. network includes seven most cited papers by authors from the United States and three by authors from other countries (Table 4). This indicates a self-contained network. Hence, H7 can be verified. In contrast, H8 is rejected because the most cited publications referred to by German authors were mainly written by authors from other countries (four from German-speaking countries and six from other countries).

\section{Conceptual embedding of the EBP discourses (H9)}

Hypothesis 9 implies different knowledge construction processes by stating that the conceptual embedding of EBP differs between the German and U.S. discourses. Figure 3 and 4 present spatial representations of the co-citation networks of both samples. The black nodes indicate highly central positions based on eigenvector and degree measures. Each cluster depicted within the whole network represents a reference list of a specific publication under study that is more or less connected with the core of the networks. As shown in Figure 3 (right), some publications are co-cited within one document but rarely connected across different documents. For instance, the distant cluster on the lower left is rarely connected to the main network. The most central (black) nodes seem to be distributed among two different groups. The enlarged network (left) shows the labels of the most central nodes. The nodes at 
the core of the network (lower right corner) appear to be the most central ones; these publications are also among the most cited publications.

INSERT FIGURE 3 ABOUT HERE

INSERT FIGURE 4 ABOUT HERE

Besides these most cited publications, other publications seem to influence the EBP discourse in the United States. For instance, the code of ethics by the National Association of Social Workers (NASW, 1996) has the highest eigenvector centrality (see Table 5). The accreditation standards by the Council on Social Work Education (CSWE, 2008) also have a high eigenvector centrality. The code of ethics and the accreditation standards are not among the most highly cited publications, nor do they show a high degree centrality. This means they are co-cited with relatively central publications. The same is true for Guyatt and Rennie's (2002) manual for evidence-based clinical practice. In addition, we identified several central publications that focus on clinical contexts (American Psychiatric Association, 2000; Chambless \& Hollon, 1998; Institute of Medicine, National Academy of Science, 2001). Contributions about critical thinking skills appear to be influential publications as well (Gambrill, 2013; Gibbs \& Gambrill, 1999).

Furthermore, the results indicate that the discussion about the role of theory in research (Marsh, 2004) and practice (Green, 2000) has an influence on the EBP discourse in the United States. Although both publications do not appear among the most central ones, they are depicted in Figure 3 due to their high eigenvector centrality (0.97). Both authors advocate the importance of theory. The same applies for the research article by Bledsoe and colleagues $(2007$; eigenvector centrality $=0.97)$, which shows that most social work training programs in the United States do not offer training for empirically supported psychotherapy. 


\section{INSERT TABLE 5 ABOUT HERE}

Figure 4 represents the co-citation network of the German sample. The whole network (right) shows two independent networks. On the rightmost side, we can see a small network that is unconnected to the main network. This means that the references found in one EBP publication were not found in any other publication. Setting aside this isolated network, the big network indicates an interconnected EBP discourse. In addition, there seems to be a core of publications that highly influence the discourses. These core publications are depicted in the enlarged image on the left side. The image shows that the publication by McNeece and Thyer (2004) has the highest degree centrality, which is confirmed by the centrality outcomes

in Table 5. The lower part of the network shows relatively dense connections between different central publications. Since direct citations and degree centrality are related to each other, the highly cited publications are found in the core network (Table 5). For example, Pawson and Tilley's (1997) influential publication about "realistic evaluation" often appears in the German EBP discourse. Their theory-driven evaluation approach emphasized the need to consider the context and underlying mechanisms when evaluating practice outcomes.

Moreover, several other highly central publications did not appear in the list of highly cited publications. For instance, a high eigenvector centrality and a high degree centrality were found for the conference report by Kindler (2005) about evidence-based diagnosis. Schmidt's (2006) article, which advocated the advantages of EBP, also has a high degree centrality. A high eigenvector centrality was also found for Grove, Zald, Lebow, Snitz, and Nelson's (2000) meta-analysis about the accuracy of clinical judgement versus mechanical prediction, as well as for Ziegler's (2003) critical publication in which he associated EBP with managerialism and the risk of losing professionalism. 
In conclusion, the founding publications of EBP are embedded differently within other scientific knowledge. The U.S. discourse and the German discourse do not share a single publication that appeared as highly central in both networks.

\section{Homogeneity of EBP discourses (H10)}

The final analysis aimed at testing our assumption that the co-citation network of the EBP discourse in the United States is more homogeneous than that of German-speaking countries. For this analysis, the co-citation network was treated as an unvalued network for two reasons: (1) to avoid the unclear definition of density in weighted networks (Scott, 2013), and (2) because the result based on an unvalued network is considered sufficient to interpret the overall connectedness of the EBP discourse. Scott (2013) emphasized the problems related to the comparison of the density of two differently sized networks. A larger network (in our case, the U.S. network) tends to result in a lower density value. Since the results even show a higher density in the larger U.S. network (0.131) than in the smaller German network (0.097), we can conclude that the U.S. discourse is based on a more homogeneous intellectual ground.

\section{Discussion}

In this section, we discuss the findings in relation to the two research questions: (1) how EBP is diffused by publications, and (2) how EBP is diffused by citations. We also relate these findings to our own experiences with EBP discourses in the United States and in Germanspeaking countries. The interpretation of science mapping results requires specific knowledge about the domain, particularly about the discourse under study (Cobo et al., 2011). In addition, the results were discussed with two domain experts from Switzerland and Germany. Although we are familiar with both EBP discourses, we want to encourage other scholars to complement our interpretations with their disciplinary experiences. 


\section{Diffusion of EBP by publications (RQ1)}

Our analysis located most of the EBP publications in the United States (H1). Out of 482 publications, 310 were written by first authors affiliated in the United States. The second most productive country is the United Kingdom, with 67 publications. Regarding the publications from German-speaking countries, we included publications in both the German and English language, which means that the numbers cannot be compared with those of other countries whose native language is not German or English. Furthermore, it would be interesting to relate the absolute number of EBP publications to the total number of social work publications of each country. Although we have not done this yet, one might speculate that, for instance, Sweden would have a high percentage compared with other countries, with 22 EBP publications out of all social work publications.

The U.S. publications include more empirical work than the German sample (H2). Although the majority of EBP publications from the United States focus on theory as well, research publications were identified three times more often within the U.S. sample than the German sample (30.8\% vs. $10.34 \%)$. This difference was found to be statistically significant which supports previous findings that revealed a stronger research orientation in the United States than in Europe (Kreisberg \& Marsh, 2016). This research orientation might be one reason why EBP could be diffused in the United States and not in German-speaking countries, since EBP can be considered atheoretical in nature (Thyer, 2013).

The comparison of the publication years of conceptual EBP publications in Germanspeaking countries and the United States revealed major differences (H3 and H4). A diffusion of EBP has never happened in German-speaking countries (H4). One explanation for this might be the preferred communication channel (H5). The majority of contributions in the German sample were not published in disciplinary journals (and only one out of 26 were published in international journals, which hinders the general exchange of knowledge), whereas most EBP publications in the United States have appeared in journals. It is important 
to consider that the results were very close to being significant $(\mathrm{p}=.054)$. Even though our hypothesis has to be formally rejected, this finding indicates a very strong tendency toward different publication habits in the United States and in German speaking countries. Since we assume that our sample was comprised of most written (conceptual) EBP publications, the descriptive difference can also be considered as meaningful evidence for future debates and research. The identified tendency of U.S. scholars to use journals as communication media might have supported the diffusion of EBP in the United States (H3). Our analysis revealed two periods of diffusion in theUnited States. The first diffusion process seemed to be triggered by the seminal work of Gambrill (1999). Although the number of publications dropped from 2004 to 2005, a second diffusion process was observed within the following years. Six years after the first EBP publication was published (Gambrill, 1999), the first publication appeared in German-speaking countries. An international conference about EBP organized by Otto and colleagues at the Centre of Social Service Studies (University of Bielefeld) in 2005 can be seen as an important driver for bringing EBP into the German scholarly discourse. Moreover, the comparison of publication years revealed that the times in which many EBP publications appeared in the United States might have led to a growth of publications in German-speaking countries. However, since the German sample is small, this assumption has to be tested in further research.

Regarding the progression of EBP publications, we want to point out what might be interpreted as a revival of EBP. In the United States, we found a peak of publications in 2008 and a decrease afterwards that lasted until 2013. However, in the following two years, the number of publications increased again. In the timeline of publications from the United States and German-speaking countries, there was a period of start-up in the United States that was followed a few years later by German-speaking countries. Furthermore, a similar pattern (although with a lower number of publications) can be discerned in the number of 
publications in the U.S. and German groups, but a time lag exists between the pattern in the United States and the pattern in German-speaking countries.

Although it is not represented in our data, EBP is currently attracting attention in German-speaking countries. Our review included articles that were published until December 2015. At the time of writing, it was already clear that an edited book would be published in 2016 with at least five chapters fulfilling our inclusion criteria (Borrmann \& Thiessen, 2016). This edited book is based on contributions from a 2015 conference held by the German Social Work Association (Deutsche Gesellschaft für Soziale Arbeit) dedicated to the topic of EBP. These observations fit our general impression that EBP has recently become more important within the discipline. However, the development has to be further observed to verify our hypothesis of a revival of EBP.

\section{Diffusion of EBP by citations (RQ2)}

Network analysis methods were used to answer the question of how knowledge about EBP has been diffused by citation patterns. The analyses identified some key players whose publications are highly influential in both the U.S. and German discourses. Specifically, different publications of Sackett and colleagues (1996, 2000) and Gambrill (1999) are central contributions. This finding is not surprising since a conceptual work about EBP without making reference to the origin of EBP would be incomplete. Other publications by Gambrill $(2001,2013)$ are frequently cited in both samples, which might be partly influenced by the "Matthew Effect." According to Merton (1968, p. 58), "the Matthew effect consists in the accruing of greater increments of recognition for particular scientific contributions to scientists of considerable repute and the withholding of such recognition from scientists who have not yet made their mark." This effect might be evident not only in citations for Gambrill but also in citations for all scholars of considerable reputation in the corresponding 
communities. Of course, this does not raise any objections to the scientific value of these contributions.

Interestingly, the publications by Sackett and Gambrill are the only ones central in both networks. None of the centrality measures identified additional publications central in both discourses. The findings imply crucial differences regarding the conceptual influence in discussing EBP in German-speaking countries and theUnited States (H6,H9).One specific finding among the German sample is the influence of the notion of reflexive professionalism on EBP, as indicated by some of the most cited titles (see "Further interpretations"). This might be caused by the specific historical evolution of German social work. The theoretical work in Germany has been strongly influenced by social pedagogy rooted in the humanities, which has led to many popular theories following a hermeneutical and phenomenological tradition (Lambers, 2012). Another influential difference regarding the constitution of social work in both countries is that U.S. social work has a strong focus on clinical contexts, particularly on "psychologically grounded practice” (Epstein, 2016, p. 495), whereas a systemic/system-theoretical paradigm is claimed to be predominant in Germany (Miller, 2010). These differences might have hindered the diffusion of EBP in German-speaking countries since both the norms of social systems, as well as the perceived compatibility of an innovation with the own values and past experiences is key for a successful diffusion process (Rogers, 2003).

Contrary to our expectations (H8), the present study provided evidence that the German discourse is not self-contained.Most of the analyzed citations refer to work outside of German-speaking countries. However, the U.S. discourse is self-contained, as indicated by the studies mainly citing publications from the United States (H7). This difference might support the findings that local standards predict the way knowledge is adapted (Knorr-Cetina, 1981). If the knowledge diffused by citations was constructed within the authors' own community, it might have a higher chance of being adapted since it already reflects the local conventions, 
methodologies, and assumptions. Given the assumption of disunified social science disciplines (Yan, 2014), knowledge from other geographical contexts might be hindered from flowing into another entity (Jaffe \& Trajtenberg, 1999), which might explain why EBP was never diffused in the German discourse. The German EBP discourse also seems less unified than the U.S. discourse, as indicated by its lower density (H10). Concrete scientific claims, represented by our unit of analysis, namely scientific publications, are less connected in German-speaking countries. Since knowledge diffusion requires knowledge flow between a sender and a recipient, this finding can further explain why EBP has been diffused in the United States but not in German-speaking countries.

\section{Further interpretations}

Before presenting further interpretations about the findings, it should be emphasized that these interpretations are based on our own educated guesses and not supported by additional research methods. Hence, a more in-depth analysis is needed to support our claims.

We have the impression that the German discourse is strongly based on criticism about the underlying concepts of EBP (e.g., Otto \& Ziegler, 2006; Webb, 2001; Ziegler, 2003). Of course, there are also central publications tending to advocate EBP (Kindler, 2005; Schmidt, 2006). However, compared with the U.S. sample, the increased number of critical publications within the German sample is remarkable. The critique might be based on an assumed hierarchy of evidence inherent in EBP, as indicated by the fact that the article of McNeece and Thyer (2004) was the most central publication (based on direct citations and degree centrality). In their article, they proposed a hierarchy of evidence and defined metaanalysis as the gold standard, followed by randomized controlled trials (RCTs). The high citation count of the work by Pawson (2002), which challenged the value of meta-analyses, might be a direct reaction to this hierarchy. The same might be the case for the high centrality of the study by Pawson and Tilley (1997), which proposed a realistic evaluation approach and 
emphasized the crucial role of context and mechanisms underlying practice outcomes. For instance, Otto, Polutta, and Ziegler (2010) used the reference to Pawson and Tilley (1997) to point out the weaknesses of RCTs in generating mechanisms of causal effects. Otto underpinned this critique by referencing Shadish, Cook, and Campbell's (2002) work about experimental research (which is also highly cited within the German sample), in which they described this weakness of experimental studies.

In conclusion, the existence of an overarching hierarchy of evidence is largely rejected (Gambrill, 2015; Rubin, 2015) even though an evidence hierarchy is undoubtedly applicable in relation to specific questions (for instance, RCTs can be seen as the gold standard for efficacy questions due to their high internal validity). In this regard, it is interesting that alternative considerations about this topic were not influential in the German network, although the topic seems to be at the core of the discourse (e.g., Fisher, 2013; Gambrill, 2006, 2015; Gray, 2001; Mullen, 2016; Petticrew \& Roberts, 2003). Much effort is put into arguing against the hierarchy, although the question of whether a hierarchy exists has, internationally speaking, tended to become obsolete. As Hüttemann (2006) and Gambrill (2015) pointed out, the discussion about qualitative versus quantitative research and positivism versus interpretivism might distract our attention from the potential of EBP to further develop the professional ground of social work. Nevertheless, there might be a well-justified critique on the concrete application of EBP, such as how social policy has adapted and then transformed the underlying ideas of EBP (cf. Otto, 2007; Ziegler, 2003). Regardless of the content of these debates, the underlying conflict between measurement and meaning might be inherent in scientific disciplines (Abbott, 2001).

In contrast to the German critical perspective, most scholars in the United States seem to agree on the importance of EBP. The underlying rationale might be as follows: First, attempts to foster social workers' application of scientific knowledge have failed. The authors of the publications under study (Jenson, 2005, p. 131, 2007, p. 570; Mullen, Bledsoe, \& 
Bellamy, 2008, p. 325) often referred to the highly influential work by Kirk and Reid (2002) to support their call to enhance EBP skills. Second, a closer look at the publications citing the most central publication, namely the code of ethics by the (NASW, 1996), shows that this code of ethics is cited because of the stated requirements for practitioners to apply researchsupported interventions (e.g., Farley et al., 2009, p. 247; Macgowan, 2006, p. 4f). This is similar to the cited accreditation standards by the CSWE (2008) that also require social workers to apply research-supported interventions. This is interesting because Gambrill (1999), in her seminal publication, criticized the frequent use by social work of these kinds of authorities to justify professionalism.

We further interpret the findings as an indicator of a conceptual focus in Germanspeaking countries and a pragmatic focus in the United States. This claim is supported by the finding that the majority of the 10 most cited publications are about how to teach or practice EBP (or also "critical thinking"; cf. Gambrill, 2013), including work about practice guidelines. Moreover, EBP in the United States seems to be influenced by the notion of EBP as a top-down approach, which is shown by the corresponding central publications (e.g., Bledsoe et al., 2007; Chambless \& Hollon, 1998). Besides the entanglement with management aspects (cf. Ioannidis, 2016), this might be one reason for the critical perspective in German-speaking countries, since a sole application of scientific knowledge is widely seen as inappropriate from a specific profession-theoretical point of view (Dewe, 2013; Otto, Polutta, \& Ziegler, 2009).

The German discourse is highly influenced by profession-theoretical work by Dewe and Otto (2012), Hüttemann (2006), Oevermann (1996), and Otto and Ziegler (2006). On the one hand, there were publications under study directly relating EBP to a reflexive professionalism (e.g., Otto et al., 2009). On the other hand, the analysis revealed several highly central publications advocating reflexivity as a feature of professional action. For instance, the publication by Dewe and Otto (2012) about this topic appeared to be highly 
central in all three analyses (direct citations and centrality measures of co-citations). The same applies to the professionalization theory by Oevermann (1996), which is related to the notion of reflexive professionalism because it requires that social workers have justifications for conducted interventions and for "substitutional problem solving," which goes along with the ability of hermeneutical judgements. The related focus on case-based and reconstructive problem-solving approaches has already been described as a specific difference between the German and U.S. EBP discourses (James, 2016). In conclusion, the results indicate that the U.S. discourse aims to answer the question of how EBP can be implemented, whereas the German discourse aims to answer the question of whether it should be implemented.

The U.S. writings seem to focus less on major theoretical work. Although two of the identified central publications emphasize the need to link theory with EBP (Green, 2000; Marsh, 2004), we could not identify a clear theoretical position towards which the discourse is (explicitly) oriented. The impression of a lack of theoretical contributions among the most central publications within the U.S. discourse must be seen as relative to the German sample. Of course, there is elaborated theoretical work embedded in several of those publications (e.g., Gambrill, 1999, 2013; Gray, 2001; Kirk \& Reid, 2002; Rosen \& Proctor, 2003). However, to infer theory patterns that mainly influence the U.S. discourse, a more in-depth analysis is needed.

\section{Limitations and conclusions}

Although the present study is, to our knowledge, the first one to empirically investigate differences between EBP discourses, the results have to be interpreted against the background of several limitations.

First, the a priori definition of two clusters can be challenged. One might argue that the German and U.S. discourses should not be assumed as separate, because different discourse boundaries might exist beyond national borders. Hence, the next step should be to 
run a cluster analysis of the whole citation database (German and U.S. publications). This additional analysis might identify different networks, particularly epistemic cultures (KnorrCetina, 1999), spanning beyond national borders.

Second, we are well aware of the existence of more publications conceptually elaborating on EBP. For instance, some publications have titles containing idiomatic expressions that do not allow us to infer the content. For instance, Schrödter (2005) entitled his article about evidence-based practice "Will the Dodo Bird Also Be Hunting Social Work?" Those titles are hard to capture through a comprehensive literature search based on bibliometric information. For the sake of scientific rigour and for our literature search to have the appropriate level of specificity and sensitivity, we decided to stick to the inclusion and exclusion criteria described earlier.

Third, our decision against normalizing the co-citation data leads to an increased likelihood of a high centrality outcome for citations occurring within a long reference list. This mechanism has to be considered especially for the German sample since it included four monographs with long reference lists (compared with one in the U.S. sample). For instance, we can assume that this effect led to the high centrality of Schmidt (2006), which only received three direct citations but was cited within two monographs.

The last limitation is the fact that the analysis regarding $\mathrm{H} 7$ and $\mathrm{H} 8$ (self-contained EBP networks) was solely based on highly cited publications. To obtain a more valid picture of the networks, a citation analysis of the whole networks is necessary.

Despite these limitations, our study provides evidence that is promising in several respects. Our results show significant differences between the German and U.S. discourse networks in terms of knowledge diffusion processes related to EBP. They show that diffusion by publications about EBP has never happened in German-speaking countries, whereas EBP has been strongly diffused in the United States. The analyses further revealed evidence about possible reasons for this difference. For instance, EBP has been related to different knowledge 
corpora important within the different geographical contexts. Hence, one can assume that the underlying conceptual understanding of EBP differs between the United States and Germanspeaking countries. These content-wise differences, as well as the finding of a more heterogeneous knowledge base in German-speaking countries, provide plausible explanations for the absence of EBP diffusion.

Our study also provides some practical implications. The results can be used by social work researchers, lecturers, historians, policy makers, and students who want to become familiar with EBP and to identify the most central EBP literature. There is widespread confusion and misconceptions about EBP (cf. McNeill, 2006; Straus \& McAlister, 2000). These misconceptions could be avoided by learning about the canonical and most influential publications. Generally speaking, and in accordance with one of the main goals of this research, the results can help clarify the confusion around EBP since knowing about different conceptual influences is key to understanding different standpoints. Therefore, it is important that scholars engaging in EBP discourse disclose their own perspectives on the underlying concepts. This need is also indicated by our literature search results, which support the findings by Shlonsky and Gibbs (2004) that the label "evidence-based" is frequently used for any empirical study investigating social work practice regardless of the quality of the evidence. This is an issue not only in social work but also in other fields (Ioannidis, 2016).

Moreover, the results might be used by practitioners actively involved in social work practice research projects. The comprehensive literature review, as well as the corresponding findings, might foster a better understanding of EBP, which is closely related to the concepts underlying social work practice research. The findings indicating the ubiquity of EBP at least in the U.S. social work might also sensitise practitioners for EBP and its relevance for social work. Finally, it is important to point out the advantage of this methodological approach and to give suggestions for future research. The finding that many relevant publications have appeared in non-electronic formats supports the assumption that automatic retrieval of 
citations might lead to biased results. Manually retrieving citations is time consuming and suitable for a limited sample size. However, it can lead to a more valid picture of a scientific discourse. Although recent attempts have been made to automatically retrieve citations from books (Kousha \& Thelwall, 2015), the manual method still remains superior for specific research questions. In general, science mapping techniques can be usefully applied to study the discipline of social work. Even though scientometric methods have rarely been used in social work research, they have become increasingly important due to the development of advanced indexing methods. For instance, Perron and colleagues' (2016) work provides a promising step towards making scientometric data applicable to social work scientists without a background in computer sciences.

Regarding the investigation of EBP discourse, we suggest the following two approaches for future research. First, network analysis methods might cluster specific discourse networks to identify "invisible colleges" (Crane, 1972) within the discipline. In terms of the comparison of the German and U.S. samples, it seems promising to look for authors who connect the dialogue and serve as transnational bridges between them (cf. Everett \& Valente, 2016). Although we plan further analyses, we are open to sending our data to interested researchers who want to investigate this issue in more detail. Second, the interpretation of science mapping results requires informed judgement by domain experts. The meaning of citation data is ambiguous, and the conclusions beyond the descriptive results can only serve as hypotheses. Hence, to acquire a more detailed picture of the concrete disciplinary argument, a discourse analysis, for instance, one oriented towards the sociologyof-knowledge approach to discourse (Keller, 2005), might complement our results and lead to a deeper understanding of EBP discourses.

\section{Acknowledgments}


We want to thank Daniel Gredig for his thought-provoking feedback on this work as well as Benedikt Lerner for his engagement in reliability testing. We want to express our gratitude to Eileen Gambrill for discussing this work and for providing her view on some issues related to EBP. We also want to thank Manuela Morsch for her hard work on data preparation, as well as two anonymous reviewers for their helpful feedback on this manuscript. Last, we want to thank Markus Eckl for his useful feedback on an earlier draft of this manuscript.

\section{Funding}

This research was supported by the Elite Network of Bavaria under Grant K-GS-2012-209.

\section{References}

Abbott, A. (1988). The system of professions: An essay on the division of expert labor. Chicago, IL: University of Chicago Press.

Abbott, A. (2001). Chaos of disciplines. Chicago, IL: University of Chicago Press. Abbott, A. (2006). Reconceptualizing knowledge accumulation in sociology. American Sociologist, 37, 57-66. Retrieved from http://www.jstor.org/stable/27700460

American Psychiatric Association (2000). Diagnostic and statistical manual of mental disorders $\left(4^{\text {th }}\right.$ ed., text rev). Washington, DC: American Psychiatric Association.

Baker, D. R. (1992). A structural analysis of social work journal network. Journal of Social Service Research, 15, 153-168. doi:10.1300/J079v15n03_09

Barber, J. G., \& Dunston, R. (2004). Evidence-based practice in Australia. In B. A. Thyer \& M. A. F. Kazi (Eds.), International perspectives on evidence-based practice in social work (pp. 183-196). Birmingham, England: Venture Press.

Barner, J. R., Holosko, M. J., \& Thyer, B. A. (2014). American social work and psychology faculty members' scholarly productivity: A controlled comparison of citation impact using the h-Index. British Journal of Social Work, 44, 2448-2458. doi:10.1093/bjsw/bct161 
Bastian, M., Heymann, S., \& Jacomy, M. (2009). Gephi: An open source software for exploring and manipulating networks. Retrieved from https://gephi.org/publications/gephi-bastian-feb09.pdf

Bavelas, A. (1950). Communication patterns in task-oriented groups. The Journal of the Acoustical Society of America, 22, 725-730. doi:10.1121/1.1906679

Bird, A. (2007). What is scientific progress? Noûs, 41, 64-89. doi:10.1111/j.14680068.2007.00638.x

Blanke, B., Bandemer, S. v., Nullmeier, F., \& Wewer, G. (2005). Handbuch zur Verwaltungsreform [Handbook of administrative reform] (3rd ed.). Wiesbaden, Germany: VS Verlag für Sozialwissenschaften.

Bledsoe, S. E., Weissman, M. M., Mullen, E. J., Ponniah, K., Gameroff, M. J., Verdeli, H., ...Wickramaratne, P. (2007). Empirically supported psychotherapy in social work training programs: Does the definition of evidence matter? Research on Social Work Practice, 17, 449-455. doi: 10.1177/1049731506299014

Bloom, M., \& Klein, W. C. (1995). Publications and citations: A study of faculty at leading schools of social work. Journal of Social Work Education, 31, 377-387. doi: 10.1080/ 10437797.1995 .10672273

Bonacich, P. (2007). Some unique properties of eigenvector centrality. Social Networks, 29, 555-564. doi:10.1016/j.socnet.2007.04.002

Borgatti, S. P. (2005). Centrality and network flow. Social Networks, 27, 55-71. doi:10.1016/j.socnet.2004.11.008

Borgatti, S. P., \& Everett, M. G. (2006). A Graph-theoretic perspective on centrality. Social Networks, 28, 466-484. doi:10.1016/j.socnet.2005.11.005

Borgatti, S. P., Everett, M. G., \& Freeman, L. C. (2002). Ucinet for Windows: Software for social network analysis. Harvard, MA: Analytic Technologies. 
Borgatti, S. P., Everett, M. G., \& Johnson, J. C. (2013). Analyzing social networks. Los Angeles, CA: Sage Publications.

Börner, K., Chen, C., \& Boyack, K. W. (2003). Visualizing knowledge domains. Annual Review of Information Science and Technology, 37, 179-255. doi:10.1002/aris.1440370106

Borrmann, S., \& Thiessen, B. (Eds.). (2016). Wirkungen Sozialer Arbeit. Potentiale und Grenzen der Evidenzbasierung für Profession und Disziplin [Impact of social work. Potentials and limitations of evidence-based practice for the profession and discipline]. Opladen, Germany: Barbara Budrich.

Boyack, K. W., \& Klavans, R. (2010). Co-citation analysis, bibliographic coupling, and direct citation: Which citation approach represents the research front most accurately? Journal of the American Society for Information Science and Technology, 61, 2389-2404. doi:10.1002/asi.21419

Brekke, J. S. (2012). Shaping a science of social work. Research on Social Work Practice, 22, 455-464. doi:10.1177/1049731512441263

Briar-Lawson, K. (2012). Critical realism: Response to Longhofer and Floersch. Research on Social Work Practice, 22, 523-528. doi:10.1177/1049731512454015

Bush, I. R., Epstein, I., \& Sainz, A. (1997). The use of social science sources in social work practice journals: An application of citation analysis. Social Work Research, 21, 45-56. doi:10.1093/swr/21.1.45

Chaffin, M., \& Friedrich, B. (2004). Evidence-based treatments in child abuse and neglect. Children and Youth Services Review, 26, 1097-1113. doi: 10.1016/j.childyouth.2004.08.008

Chambless, D. L., Baker, M. J., Baucom, D. H., Beutler, L. E., Calhoun, K. S., CritsChristoph, P., ... Haaga, D. A. F. (1998). Update on empirically validated therapies, II. 
The Clinical Psychologist, 51, 3-16. Retrieved from https://pdfs.semanticscholar.org/9cd0/1d8fcd52cec4d9389d5846c18e69c6f6f8e6.pdf

Chambless, D. L., \& Hollon, S. D. (1998). Defining empirically supported therapies. Journal of Consulting and Clinical Psychology, 66, 7-18. Retrieved from https://www.div12.org/wp-content/uploads/2016/10/Defining-Empirically-SupportedTherapies-1.pdf

Chen, C., \& Hicks, D. (2004). Tracing knowledge diffusion. Scientometrics, 59, 199-211. doi:10.1023/B:SCIE.0000018528.59913.48

Cobo, M. J., López-Herrera, A. G., Herrera-Viedma, E., \& Herrera, F. (2011). Science mapping software tools: Review, analysis, and cooperative study among tools. Journal of the American Society for Information Science and Technology, 62(7), 1382-1402. doi:10.1002/asi.21525

Council on Social Work Education (2008). Educational policy and accreditation standards. Retrieved from http://www.cswe.org/File.aspx?id=41861

Crane, D. (1972). Invisible colleges; Diffusion of knowledge in scientific communities. Chicago, IL: University of Chicago Press.

Cronin, B. (1994). Tiered citation and measures of document similarity. Journal of the American Society for Information Science, 45, 537-538. doi:10.1002/(SICI)10974571(199408)45:7<537::AID-ASI8>3.0.CO;2-Q

Davis, P. M. (2011). Open access, readership, citations: A randomized controlled trial of scientific journal publishing. FASEB Journal, 25, 2129-2134. doi:10.1096/fj.11-183988 de Solla Price, D. J. (1965). Networks of scientific papers. Science, 149, 510-515. doi:10.1126/science.149.3683.510

Dewe, B. (2013). Reflexive Sozialarbeit im Spannungsfeld von evidenzbasierter Praxis und demokratischer Rationalität—Plädoyer für die handlungslogische Entfaltung reflexiver Professionalität [Reflexive social work in the field of tension of evidence-based practice 
and democratic rationality-Plea for the action-logic evolvement of reflexive professionality]. In R. Becker-Lenz (Ed.), Professionalität in der Sozialen Arbeit. Standpunkte, Kontroversen, Perspektiven [Professionality in social work. Standpoints, controversies, perspectives] (3rd ed., pp. 94-116). Wiesbaden, Germany: Springer VS.

Dewe, B., \& Otto, H.-U. (2012). Reflexive Sozialpädagogik. Grundstrukturen eines neuen Typs dienstleistungsorientierten Professionshandelns [Reflexive social pedagogy. Foundation of a new type of service-oriented professional action]. In W. Thole (Ed.), Grundriss Soziale Arbeit. Ein einführendes Handbuch [Layout of social work. An introducing handbook] (4th ed., pp. 197-218). Wiesbaden, Germany: VS Verlag für Sozialwissenschaften.

Downing, K. (1996). Probation training, cognition and crime: Uses and abuses of theory. Social Work Education, 15(4), 65-75. doi:10.1080/02615479611220351

Epstein, W. M. (2016). Strict slaves of slogans: Response to "The Social Work Cartel." Research on Social Work Practice, 26, 494-497. doi:10.1177/1049731515615679

Everett, M. G., \& Borgatti, S. P. (2013). The dual-projection approach for two-mode networks. Social Networks, 35, 204-210. doi:10.1016/j.socnet.2012.05.004

Everett, M. G., \& Valente, T. W. (2016). Bridging, brokerage and betweenness. Social Networks, 44, 202-208. doi:10.1016/j.socnet.2015.09.001

Evidence-Based Medicine Working Group. (1992). Evidence-based medicine. A new approach to teaching the practice of medicine. Journal of the American Medical Association, 268, 2420-2425. doi:10.1001/jama.1992.03490170092032

Farley, A. J., Feaster, D., Schapmire, T. J., D’Ambrosio, J. G., Bruce, L. E., Oak, C. S., \& Sar, B. K. (2009). The challenges of implementing evidence based practice: Ethical considerations in practice, education, policy, and research. Social Work \& Society, 7, 246-259. Retrieved from http://www.socwork.net/sws/article/view/76/135 
Fisher, M. (2013). Beyond evidence-based policy and practice: Reshaping the relationship between research and practice. Social Work \& Social Sciences Review, 16(2), 20-36. doi:10.1921/903160201

Fruchterman, T. M. J., \& Reingold, E. M. (1991). Graph drawing by force-directed placement. Software: Practice and Experience, 21, 1129-1164. doi:10.1002/spe.4380211102

Gambrill, E. (1999). Evidence-based practice: An alternative to authority-based practice. Families in Society: The Journal of Contemporary Social Services, 80, 341-350. doi:10.1606/1044-3894.1214

Gambrill, E. (2001). Social work: An authority-based profession. Research on Social Work Practice, 11, 166-175. doi:10.1177/104973150101100203

Gambrill, E. (2006). Evidence-based practice and policy: Choices ahead. Research on Social Work Practice, 16, 338-357. doi:10.1177/1049731505284205

Gambrill, E. (2010). Evidence-based practice and the ethics of discretion. Journal of Social Work, 11, 26-48. doi:10.1177/1468017310381306

Gambrill, E. (2013). Social work practice: A critical thinker's guide (3rd ed.). New York, NY: Oxford University Press.

Gambrill, E. (2015). Integrating research and practice: Distractions, controversies, and options for moving forward. Research on Social Work Practice, 25, 510-522. doi:10.1177/1049731514544327

Garfield, E. (1972). Citation analysis as a tool in journal evaluation: Journals can be ranked by frequency and impact of citations for science policy studies. Science, 178, 471-479. doi:10.1126/science.178.4060.471

Garfield, E. (1994a). The relationship between citing and cited publication: A question of relatedness. Retrieved from http://wokinfo.com/essays/relationship-citedpublications/\#ref.8 
Garfield, E. (1994b). Scientography: Mapping the tracks of science. Retrieved from http://wokinfo.com/essays/scientography-mapping-science/

Garfield, E. (1998). Random thoughts on citationology. Its theory and practice.

Scientometrics, 43, 69-76. doi:10.1007/BF02458396

Garfield, E. (2001). From bibliographic coupling to co-citation analysis via algorithmic historiobibliography. Retrieved from http://www.garfield.library.upenn.edu/papers/drexelbelvergriffith92001.pdf

Gibbs, L. (2003). Evidence-based practice for the helping professions: A practical guide with integrated multimedia (Vol. 1). Pacific Grove, CA: Brooks/Cole-Thomson Learning.

Gibbs, L. E., \& Gambrill, E. D. (1999). Critical thinking for social workers: Exercises for the helping professions. Thousand Oaks, CA: Pine Forge Press.

Gmür, M. (2003). Co-citation analysis and the search for invisible colleges: A methodological evaluation. Scientometrics, 57, 27-57. doi:10.1023/A:1023619503005

Gray, J. A. M. (2001). Evidence-based healthcare: How to make health policy and management decisions (2nd ed). New York, NY: Churchill Livingston.

Green, J. (2000). The role of theory in evidence-based health promotion practice. Health Education Research, 15, 125-129. doi:10.1093/her/15.2.125

Greenberg, S. A. (2009). How citation distortions create unfounded authority: Analysis of a citation network. British Medical Journal, 339(2680), 210-213. doi:10.1136/bmj.b2680

Grove, W. M., Zald, D. H., Lebow, B. S., Snitz, B. E., \& Nelson, C. (2000). Clinical versus mechanical prediction: A meta-analysis. Psychological Assessment, 12, 19-30. doi:10.1037//1040-3590.12.1.19

Guyatt, G., \& Rennie, D. (2002). Users' guides to the medical literature: A manual for evidence-based clinical practice. Chicago, IL: American Medical Association.

Harter, S. P., Nisonger, T. E., \& Weng, A. (1993). Semantic relationships between cited and citing articles in library and information science journals. Journal of the American 
Society for Information Science, 44, 543-552. doi:10.1002/(SICI)1097-

4571(199310)44:9<543::AIDASI4>3.0.CO;2-F

Haythornthwaite, C. (1996). Social network analysis: An approach and technique for the study of information exchange. Library \& Information Science Research, 18, 323-342. doi:10.1016/S0740-8188(96)90003-1

Healy, K. (2013). A co-citation network for philosophy. Retrieved from https://kieranhealy.org/blog/archives/2013/06/18/a-co-citation-network-for-philosophy/

Hess, D. J. (1997). Science studies: An advanced introduction. New York, NY: NYU press.

Hirsch, J. E. (2005). An index to quantify an individual's scientific research output.

Proceedings of the National Academy of Sciences of the United States of America, 102, 16569-16572. doi:10.1073/pnas.0507655102

Hodge, D. R., Lacasse, J. R., \& Benson, O. (2012). Influential publications in social work discourse: The 100 most highly cited articles in disciplinary journals: 2000-09. British Journal of Social Work, 42, 765-782. doi:10.1093/bjsw/bcr093

Holden, G., Rosenberg, G., Barker, K., \& Lioi, J. (2009). Research on social work practice: A bibliometric evaluation of the first decade. Research on Social Work Practice, 20, 11-20. doi:10.1177/1049731509332877

Howard, M. O., Himle, J., Jenson, J. M., \& Vaughn, M. G. (2009). Revisioning social work clinical education: Recent developments in relation to evidence-based practice. Journal of Evidence-based Social Work, 6, 256-273. doi:10.1080/15433710802686963

Howard, M. O., \& Jensen, J. (1999). Clinical practice guidelines: Should social work develop them? Research on Social Work Practice, 9, 283-301. doi:10.1177/104973159900900302

Howard, M. O., McMillen, C. J., \& Pollio, D. F. (2003). Teaching evidence-based practice: Toward a new paradigm for social work education. Research on Social Work Practice, 13, 234-259. doi:10.1177/1049731502250404 
Hüttemann, M. (2006). Evidence-based practice_Ein Beitrag zur Professionalisierung Sozialer Arbeit? [Evidence-based practice-A contribution to the professionalization of social work?]. Neue Praxis, 36, 156-167.

Institute of Medicine, National Academy of Science. (2001). Crossing the quality chasm: A new health system for the 21st century. Washington, DC: National Academy Press.

Ioannidis, J. P. (2016). Evidence-based medicine has been hijacked: A report to David Sackett. Journal of Clinical Epidemiology, 73, 82-86. doi:10.1016/j.jclinepi.2016.02.012

Jaffe, A. B., \& Trajtenberg, M. (1999). International knowledge flows: Evidence from patent citations. Economics of Innovation and New Technology, 8, 105-136. doi:10.1080/10438599900000006

James, S. (2016). "Inside the belly of the beast"-Möglichkeiten und Grenzen der evidenzbasierten Praxis ["Inside the belly of the beast"-Opportunities and limitations of evidence-based practice]. In S. Borrmann \& B. Thiessen (Eds.), Wirkungen Sozialer Arbeit. Potentiale und Grenzen der Evidenzbasierung für Profession und Disziplin [Impact of social work. Potentials and limitations of evidence-based practice for profession and discipline] (pp. 143-160). Opladen, Germany: Barbara Budrich.

Jenson, J. M. (2005). Connecting science to intervention: Advances, challenges, and the promise of evidence-based practice. Social Work Research, 29, 131-135. Retrieved from http://www.jstor.org/stable/42659593

Jenson, J. M. (2007). Evidence-based practice and the reform of social work education: A response to Gambrill and Howard and Allen-Meares. Research on Social Work Practice, 17, 569-573. doi:10.1177/1049731507300236

Keller, R. (2005). Analysing discourse. An approach from the sociology of knowledge. Forum Qualitative Social Research, 6. Retrieved from http://www.qualitativeresearch.net/index.php/fqs/article/view/19/41 
Kindler, H. (2005). Evidenzbasierte Diagnostik in der Sozialen Arbeit [Evidence-based diagnosis in social work]. Neue Praxis, 35, 540-545.

Kirk, S. A., \& Reid, W. J. (2002). Science and social work: A critical appraisal. New York, NY: Columbia University Press.

Knorr-Cetina, K. (1981). Manufacture of knowledge: An essay on the constructivist and contextual nature of science. Oxford, England: Pergamon.

Knorr-Cetina, K. (1999). Epistemic cultures: How the sciences make knowledge. Cambridge, MA: Harvard University Press.

Kousha, K., \& Thelwall, M. (2015). An automatic method for extracting citations from Google Books. Journal of the Association for Information Science and Technology, 66, 309-320. doi:10.1002/asi.23170

Kreisberg, N., \& Marsh, J. C. (2016). Social work knowledge production and utilisation: An international comparison. British Journal of Social Work, 46, 599-618. doi:10.1093/bjsw/bcu147

Lambers, H. (2012). Theorien Sozialer Arbeit: Ein Überblick und Vergleich [Social work theories: An overview and comparison]. Stuttgart, Germany: UTB.

Leydesdorff, L. (2007). Should co-occurrence data be normalized? A rejoinder. Journal of the American Society for Information Science and Technology, 58, 2411-2413. doi:10.1002/asi.20691

Leydesdorff, L., \& Milojevic S. (2015). Scientometrics. In M. Lynch (Ed.), International encyclopedia of social and behavioral sciences (pp. 322-327). Amsterdam, Netherlands: Elsevier. doi:10.1016/B978-0-08-097086-8.85030-8

Leydesdorff, L., \& Vaughan, L. (2006). Co-occurrence matrices and their applications in information science: Extending ACA to the web environment. Journal of the American Society for Information Science and Technology, 57, 1616-1628. doi:10.1002/asi.20335 
Ligon, J., Thyer, B. A., \& Cobb, A. (2012). Academic affilitations of social work journal article authors. Journal of Social Work Education, 48, 613-622. doi:10.5175/JSWE.2012.201000150

Lindsey, D., \& Kirk, S. A. (1992). The role of social work journals in the development of a knowledge base for the profession. Social Service Review, 66, 295-310. Retrieved from http://www.jstor.org/stable/30012167

Liu, Y., \& Rousseau, R. (2010). Knowledge diffusion through publications and citations: A case study using ESI-fields as unit of diffusion. Journal of the American Society for Information Science and Technology, 61, 340-351. doi:10.1002/asi.21248

Longhofer, J., \& Floersch, J. (2012). The coming crisis in social work: Some thoughts on social work and science. Research on Social Work Practice, 22, 499-519. doi:10.1177/1049731512445509

Macgowan, M. J. (2006). Evidence-based group work: A framework for advancing best practice. Journal of Evidence-Based Social Work, 3, 1-21. doi:10.1300/J394v03n01_01

Marsh, J. C. (2004). Theory-driven versus theory-free research in empirical social work practice. In H. E. Briggs \& T. L. Rzepnicki (Eds.), Using evidence in social work practice: Behavioral perspectives (pp. 20-35). Chicago, IL: Lyceum Books.

Marsh, J. C. (2012). Response: From fish and bicycles to a science of social work. Research on Social Work Practice, 22, 465-467. doi:10.1177/1049731512441837

Martínez, M. A., Cobo, M. J., Herrera, M., \& Herrera-Viedma, E. (2015). Analyzing the scientific evolution of social work using science mapping. Research on Social Work Practice, 25, 257-277. doi:10.1177/1049731514522101

McNeece, C. A., \& Thyer, B. A. (2004). Evidence-based practice and social work. Journal of Evidence-Based Social Work, 1, 7-25. doi:10.1300/J394v01n01_02 
McNeill, T. (2006). Evidence-based practice in an age of relativism: Toward a model for practice. Social Work, 51, 147-156. Retrieved from http://www.jstor.org/stable/23721279

Merton, R. K. (1968). The Matthew effect in science: The reward and communication systems of science are considered. Science, 159(3810), 56-63. doi:10.1126/science.159.3810.56

Miller, T. (2010). Netzwerkgesellschaft und Systemtheorie. Systemische Soziale Arbeit, 1, $41-58$.

Mullen, E. J. (2016). Reconsidering the 'idea' of evidence in evidence-based policy and practice. European Journal of Social Work, 19, 310-335.

doi:10.1080/13691457.2015.1022716

Mullen, E. J., Bledsoe, S. E., \& Bellamy, J. L. (2008). Implementing evidence-based social work practice. Research on Social Work Practice, 18, 325-338. doi:10.1177/1049731506297827

National Association of Social Workers. (1996). Code of ethics. Retrieved from https://www.socialworkers.org/pubs/code/default.asp

Noyons, E. C. (1999). Bibliometric mapping as a science policy and research management tool. Leiden, Netherlands: DSWO Press. Retrieved from https://openaccess.leidenuniv.nl/bitstream/handle/1887/38308/noyons_1999.pdf?sequenc $\mathrm{e}=3$

Oevermann, U. (1996). Theoretische Skizze einer revidierten Theorie professionalisierten Handelns [Theoretical sketch of a revised theory of professional action]. In A. Combe \& W. Helsper (Eds.), Pädagogische Professionalität: Untersuchungen zum Typus pädagogischen Handelns [Pedagogical professionality: Investigations of the pedagogical action type] (2nd ed., pp. 70-182). Frankfurt am Main, Germany: Suhrkamp. 
Okpych, N. J., \& Yu, J. L.-H. (2014). A historical analysis of evidence-based practice in social work: The unfinished journey toward an empirically grounded profession. Social Service Review, 88, 3-58. doi:10.1086/674969

Opsahl, T., Agneessens, F., \& Skvoretz, J. (2010). Node centrality in weighted networks: Generalizing degree and shortest paths. Social Networks, 32(3), 245-251. doi:10.1016/j.socnet.2010.03.006

Otto, H.-U. (2007). Zum aktuellen Diskurs um Ergebnisse und Wirkungen im Feld der Sozialpädagogik und Sozialarbeit—Literaturvergleich nationaler und internationaler Diskussion [About the current discourse about results and impact in the field of social pedagogy and social work-Literature review about the national and international discussions]. Berlin, Germany: Selbstverl.

Otto, H.-U., Polutta, A., \& Ziegler, H. (2009). Reflexive professionalism as a second generation of evidence-based practice: Some considerations on the special issue "What Works? Modernizing the Knowledge-Base of Social Work." Research on Social Work Practice, 19, 472-478. doi:10.1177/1049731509333200

Otto, H.-U., Polutta, A., \& Ziegler, H. (2010). Zum Diskurs um evidenzbasierte Soziale Arbeit [About the discourse about evidence-based practice]. In H. U. Otto, A. Polutta, \& H. Ziegler (Eds.), What Works-Welches Wissen braucht die Soziale Arbeit? Zum Konzept evidenzbasierter Praxis [What works-Which knowledge does social work need? About the concept of evidence-based practice] (pp. 7-28). Opladen, Germany: Barbara Budrich.

Otto, H.-U., \& Ziegler, H. (2006). Managerielle Wirkungsorientierung und der demokratische Nutzwert professioneller Sozialer Arbeit [Managerial impact orientation and the democratic utilizable value of professional social work]. In T. Badawia, H. Luckas, \& H. Müller (Eds.), Das Soziale gestalten [Design the social] (pp. 96-112). Wiesbaden, Germany: Verlag für Sozialwissenschaften. 
Pawson, R. (2002). Evidence-based policy: In search of a method. Evaluation, 8, 157-181. doi:10.1177/1358902002008002512

Pawson, R., \& Tilley, N. (1997). Realistic evaluation. London, England: Sage Publications.

Perron, B. E., Victor, B. G., Hodge, D. R., Salas-Wright, C. P., Vaughn, M. G., \& Taylor, R. J. (2016). Laying the foundations for scientometric research: A data science approach. Research on Social Work Practice. Advance online publication. doi:10.1177/1049731515624966

Peters, H. P. F., Braam, R. R., \& van Raan, A. F. J. (1995). Cognitive resemblance and citation relations in chemical engineering publications. Journal of the American Society for Information Science, 46, 9-21. doi:10.1002/(SICI)1097-4571(199501)46:1<9::AIDASI2>3.0.CO;2-3

Petticrew, M., \& Roberts, H. (2003). Evidence, hierarchies, and typologies: Horses for courses. Journal of Epidemiology \& Community Health, 57, 527-529. doi:10.1136/jech.57.7.527

Petticrew, M., \& Roberts, H. (2006). Systematic reviews in the social sciences: A practical guide. Malden, MA: Blackwell Publishing.

Proctor, E. K., \& Rosen, A. (2003). The structure and function of social work practice guidelines. In A. Rosen \& E. K. Proctor (Eds.), Developing practice guidelines for social work interventions: Issues, methods, and research agenda (pp. 108-127). New York, NY: Columbia University Press.

Reid, W. J. (1994). The empirical practice movement. Social Service Review, 68, 165-184.

Rogers, E. M. (2003). Diffusion of innovations (5th ed.). New York, NY: Free Press.

Rosen, A., \& Proctor, E. K. (Eds.). (2003). Developing practice guidelines for social work interventions: Issues, methods, and research agenda. New York, NY: Columbia University Press. 
Rubin, A. (2015). Efforts to bridge the gap between research and practice in social work: Precedents and prospects: Keynote address at the bridging the gap symposium. Research on Social Work Practice, 25, 408-414. doi:10.1177/1049731514535852

Rubin, A., \& Babbie, E. (2005). Research methods for social work (5th ed.). Belmont, CA: Thompson Brooks/Cole.

Rubin, A., \& Parrish, D. (2006). Views of evidence-based practice among faculty in master of social work programs: A national survey. Research on Social Work Practice, 17, 110122. doi: $10.1177 / 1049731506293059$

Sackett, D. L., Rosenberg, W. M. C., Gray, J. A. M., Haynes, R. B., \& Richardson, W. S. (1996). Evidence based medicine: What it is and what it isn't. British Medical Journal, 312(7023), 71-72. doi:10.1136/bmj.312.7023.71

Sackett, D. L., Straus, S. E., Richardson, W. S., Rosenberg, W., \& Haynes, B. R. (1997). Evidence-based medicine. How to practice and teach EBM. London, England: Churchill Livingston.

Sackett, D. L., Straus, S. E., Richardson, W. S., Rosenberg, W., \& Haynes, B. R. (2000). Evidence-based medicine. How to practice and teach EBM (2nd ed.). London, England: Churchill Livingston.

Schmidt, R. (2006). Auf dem Weg zur evidenzbasierten Sozialen Arbeit. Ein Impuls zu mehr und zu anderer Fachlichkeit [On the way to an evidence-based social work. An impulse to more and another professionality]. Blätter der Wohlfahrtspflege, 159, 99-103.

Schrödter, M. (2005). Will the dodo bird also be hunting social work? In P. Sommerfeld \& P. Herzog (Eds.), Evidence-based social work-Towards a new professionalism? (pp. 5360). Bern, Switzerland: Lang.

Scott, J. (2013). Social network analysis: A handbook (3rd ed.). Los Angeles, CA: Sage Publications. 
Shadish, W. R., Cook, T. D., \& Campbell, D. T. (2002). Experimental and quasi-experimental designs for generalized causal inference. Boston, MA: Houghton Mifflin.

Shaw, I. (2014). A science of social work? Response to John Brekke. Research on Social Work Practice, 24, 524-526. doi:10.1177/1049731514543408

Shaw, I. (2016). Science and social work: A sketch. European Journal of Social Work, 19, 336-353. doi:10.1080/13691457.2015.1074552

Sheldon, B., \& Chilvers, R. (2004). Evidence-based practice in England. In B. A. Thyer \& M. A. F. Kazi (Eds.), International perspectives on evidence-based practice in social work (pp. 45-80). Birmingham, England: Venture Press.

Shiffrin, R. M., \& Borner, K. (2004). Mapping knowledge domains. Proceedings of the National Academy of Sciences of the United States of America, 101(Suppl 1), 5183 5185. doi:10.1073/pnas.0307852100

Shlonsky, A., \& Gibbs, L. (2004). Will the real evidence-based practice please stand up? Teaching the process of evidence-based practice to the helping professions. Brief Treatment and Crisis Intervention, 4, 137-153. doi:10.1093/brief-treatment/mhh011

Small, H. (1999). Visualizing science by citation mapping. Journal of the American Society for Information Science, 50, 799-813. doi:10.1002/(SICI)10974571(1999)50:9<799::AID-ASI9>3.0.CO;2-G

Sommerfeld, P. (2014). Social work as an action science: A perspective from Europe. Research on Social Work Practice, 24, 586-600. doi:10.1177/1049731514538523 Sommerfeld, P. (2016). Evidenzbasierung als ein Beitrag zum Aufbau eines professionellen Wissenskorpus in der Sozialen Arbeit [Evidence-based practice as a contribution to develop a professional knowledge corpus in social work]. In S. Borrmann \& B. Thiessen (Eds.), Wirkungen Sozialer Arbeit. Potentiale und Grenzen der Evidenzbasierung für Profession und Disziplin [Impact of social work. Potentials and limitations of evidence- 
based practice for profession and discipline] (pp. 21-41). Opladen, Germany: Barbara Budrich.

Staub-Bernasconi, S. (2013). Der Professionalisierungsdiskurs zur Sozialen Arbeit (SA/SP) im deutschsprachigen Kontext im Spiegel internationaler Ausbildungsstandards [The professionalization discourse in social work in the German context in relation to the international education standards]. In R. Becker-Lenz (Ed.), Professionalität in der Sozialen Arbeit. Standpunkte, Kontroversen, Perspektiven [Professionality in social work. Standpoints, controversies, perspectives] (3rd ed., pp. 23-48). Wiesbaden, Germany: Springer VS.

Straus, S. E., \& McAlister, F. A. (2000). Evidence-based medicine: A commentary on common criticisms. Canadian Medical Association Journal, 163, 837-841. Retrieved from https://www.ncbi.nlm.nih.gov/pmc/articles/PMC80509/

Straus, S. E., Richardson, W. S., Glasziou, P., \& Haynes, R. B. (Eds.). (2005). Evidencebased medicine: How to practice and teach EBM (3rd ed.). New York, NY: Churchill Livingston.

Sundell, K., Soydan, H., Tengvald, K., \& Anttila, S. (2010). From opinion-based to evidencebased social work: The Swedish case. Research on Social Work Practice, 20, 714-722. doi:10.1177/1049731509347887

Szulanski, G. (1996). Exploring internal stickiness: Impediments to the transfer of best practice within the firm. Strategic Management Journal, 17(S2), 27-43. doi:10.1002/smj.4250171105

Thyer, B. A. (2013). Evidence-based practice or evidence-guided practice: A rose by any other name would smell as sweet. Families in Society, 94, 79-84. doi:10.1606/10443894.4283 
Thyer, B. A. (2015). Preparing current and future practitioners to integrate research in real practice settings. Research on Social Work Practice, 25, 463-472. doi:10.1177/1049731514538105

United Nations Educational, Scientific and Cultural Organization. (2005). Towards knowledge societies. Retrieved from http://unesdoc.unesco.org/images/0014/001418/141843e.pdf

United Nations Educational, Scientific and Cultural Organization (2014). Building inclusive knowledge societies. Retrieved from http://unesdoc.unesco.org/images/0022/002264/226425e.pdf

Valente, T. W., Coronges, K., Lakon, C., \& Costenbader, E. (2008). How correlated are network centrality measures? Connections, 28, 16-26. Retrieved from https://www.ncbi.nlm.nih.gov/pmc/articles/PMC2875682/

Välimaa, J., \& Hoffman, D. (2008). Knowledge society discourse and higher education. Higher Education, 56, 265-285. doi:10.1007/s10734-008-9123-7

Wallace, M. L., Gingras, Y., \& Duhon, R. (2009). A new approach for detecting scientific specialties from raw cocitation networks. Journal of the American Society for Information Science and Technology, 60, 240-246. doi:10.1002/asi.20987

Waltman, L., \& van Eck, N. J. (2007). Some comments on the question whether cooccurrence data should be normalized. Journal of the American Society for Information Science and Technology, 58, 1701-1703. doi:10.1002/asi.20647

Webb, S. A. (2001). Some considerations on the validity of evidence-based practice in social work. British Journal of Social Work, 31, 57-79. doi:10.1093/bjsw/31.1.57

White, H. D., \& Griffith, B. C. (1981). Author cocitation: A literature measure of intellectual structure. Journal of the American Society for Information Science, 32, 163-171. 
Yan, E. (2014). Finding knowledge paths among scientific disciplines. Journal of the Association for Information Science and Technology, 65, 2331-2347. doi:10.1002/asi.23106

Yan, E., \& Ding, Y. (2009). Applying centrality measures to impact analysis: A co-authorship network analysis. Journal of the American Society for Information Science and Technology, 60, 2107-2118. doi:10.1002/asi.v60:10

Ziegler, H. (2003). Diagnose, Macht, Wissen und "What Works?"-Die Kunst dermaßen zu regieren [Diagnosis, power, knowledge and "what works?"- The art to govern insomuch]. Widersprüche, 23, 101-115. 
Table 1. Operationalization of Variables.

\begin{tabular}{|c|c|c|}
\hline Hypothesis & (Dependent) variable & Operationalization \\
\hline \multicolumn{3}{|c|}{$\begin{array}{c}\text { Research Question (RQ) 1: How has the knowledge about EBP been diffused by } \\
\text { publications? }\end{array}$} \\
\hline $\begin{array}{l}\text { H1: The core of the EBP } \\
\text { debate is located in the } \\
\text { United States. }\end{array}$ & Discourse dominance & $\begin{array}{l}\mathrm{H} 1 \text { is rejected if most EBP } \\
\text { publications do not have first } \\
\text { authors from the United } \\
\text { States. }\end{array}$ \\
\hline $\begin{array}{l}\text { H2: EBP publications from } \\
\text { the United States apply a } \\
\text { research focus, and those } \\
\text { from GER apply a theory } \\
\text { focus. }\end{array}$ & Focus of publication & $\begin{array}{l}\mathrm{H} 2 \text { is rejected if there is a } \\
\text { significant difference } \\
\text { between the U.S. discourse } \\
\text { and the GER discourse in } \\
\text { terms of the focus of their } \\
\text { publications. }\end{array}$ \\
\hline $\begin{array}{l}\mathrm{H} 3 \text { and } \mathrm{H} 4 \text { : EBP has been } \\
\text { diffused by publications in } \\
\text { the United States but not in } \\
\text { GER. }\end{array}$ & Diffusion of EBP & $\begin{array}{l}\mathrm{H} 3 \text { is rejected if the number } \\
\text { of EBP publications has not } \\
\text { exponentially increased in } \\
\text { the United States. } \\
\mathrm{H} 4 \text { is rejected if the number } \\
\text { of EBP publications has } \\
\text { exponentially increased in } \\
\text { GER. }\end{array}$ \\
\hline $\begin{array}{l}\text { H5: EBP is spread mainly by } \\
\text { journal publications in the } \\
\text { United States and by other } \\
\text { publication formats in GER. }\end{array}$ & Publication format & $\begin{array}{l}\text { H5 is rejected if the } \\
\text { publication format } \\
\text { significantly differs between } \\
\text { the U.S. network and the } \\
\text { German network. }\end{array}$ \\
\hline
\end{tabular}

Research Question (RQ) 2: How has the knowledge about EBP been diffused by citations?

H6: The EBP discourses in Influence of different schools H6 is rejected if the most the United States and in GER of thought cited publications within the

are influenced by different

schools of thought.

H7 and H8: Both discourses Self-contained

are self-contained.

U.S. and GER discourses do not differ.

$\mathrm{H} 7$ is rejected if a minority of the most cited publications in the U.S. sample are written by authors from the United States.

$\mathrm{H} 8$ is rejected if a minority of the most cited publications in the German sample are written by authors from GER.

H9: The conceptual Conceptual embedding embedding of the EBP discourses differs between the United States and GER. H10: The EBP discourse in the United States is more homogeneous than that of GER.
H9 is rejected if the most central publications within the co-citations networks of both discourses are identical.

Discourse homogeneity $\mathrm{H} 10$ is rejected if the cocitation network of the EBP discourse in GER is denser than that of the United States. 
Note. GER = German-speaking countries. 
Table 2. Identified EBP Publications Worldwide $(\mathrm{N}=482)$.

\begin{tabular}{lc}
\hline Country & Number of Publications \\
\hline United States & 310 \\
United Kingdom & 67 \\
Canada & 24 \\
Germany & 22 \\
Australia & 18 \\
Sweden & 13 \\
Switzerland & 9 \\
Israel & 4 \\
Netherlands & 3 \\
China & 2 \\
Hong Kong & 2 \\
Denmark & 2 \\
Finland & 2 \\
South Korea & 1 \\
Romania & 1 \\
Austria & 1 \\
Italy & 1 \\
\hline
\end{tabular}


Table 3. Publication Format of Conceptual EBP Publications.

\begin{tabular}{lll}
\hline Source & & \\
\hline First author's affiliation in the United States & Number of publications & $\%$ \\
\hline Edited book chapter & 66 & 31.58 \\
Monograph & 21 & 10.05 \\
Journal of Evidence-Based (-Informed) Social Work & 21 & 10.05 \\
Research on Social Work Practice & 21 & 10.05 \\
Families in Society & 8 & 3.83 \\
Journal of Social Work Education & 7 & 3.35 \\
Clinical Social Work Journal & 6 & 2.87 \\
Social Work & 5 & 2.39 \\
Journal of Social Work & 4 & 1.91 \\
Social Work Research & 4 & 1.91 \\
Brief Treatment and Crisis Intervention & 3 & 1.44 \\
Journal of Teaching in Social Work & 3 & 1.44 \\
American Journal of Orthopsychiatry & 2 & 0.96 \\
British Journal of Social Work & 2 & 0.96 \\
Child Welfare & 2 & 0.96 \\
European Journal of Social Work & 2 & 0.96 \\
Journal of Religion \& Spirituality in Social Work & 2 & 0.96 \\
Smith College Studies in Social Work & 2 & 0.96 \\
Social Service Review & 2 & 0.96 \\
Social Work in Mental Health & 2 & 0.96 \\
Other journals (with one publication each) & 24 & 11.48 \\
Total & 209 & 100.00 \\
\hline First author's affiliation in German-speaking & & \\
countries & 12 & 46.15 \\
\hline Edited book chapter & 4 & 15.38 \\
Monograph & 2 & 7.69 \\
Blätter der Wohlfahrtspflege & 6 & 23.10 \\
Research on Social Work Practice & 26 & 100.00 \\
Other journals (one publication each) & & \\
\hline Total & & \\
& &
\end{tabular}


Table 4. Most Cited References Within Conceptual EBP Publications.

\begin{tabular}{ll}
\hline Publication & Number of Citations \\
\hline Most cited publications by authors from the United States (total \\
citations = 1,679)
\end{tabular}


Table 5. Centrality Measures of Co-citation Networks.

\begin{tabular}{|c|c|c|c|}
\hline Publication & (Weighted) Degree & Publication & Eigenvector \\
\hline \multicolumn{4}{|c|}{ Ten Most Central Publications in the United States } \\
\hline Sackett et al., 2000 & 837 & NASW, 1996 & 1.00 \\
\hline Gibbs, 2003 & 790 & Gambrill, 2013 & .99 \\
\hline NASW, 1996 & 781 & $\begin{array}{l}\text { Institute of Medicine, } \\
2001\end{array}$ & .99 \\
\hline Gambrill, 2013 & 766 & $\begin{array}{l}\text { American Psychiatric } \\
\text { Association, } 2000\end{array}$ & .99 \\
\hline $\begin{array}{l}\text { Institute of Medicine, } \\
2001\end{array}$ & 705 & $\begin{array}{l}\text { Chambless et al., } \\
1998\end{array}$ & .99 \\
\hline $\begin{array}{l}\text { American Psychiatric } \\
\text { Association, } 2000\end{array}$ & 696 & Kirk \& Reid, 2002 & .98 \\
\hline Gambrill, 1999 & 663 & $\begin{array}{l}\text { Rubin \& Babbie, } \\
2005\end{array}$ & .98 \\
\hline Sackett et al., 1996 & 647 & $\begin{array}{l}\text { Guyatt \& Rennie, } \\
2002\end{array}$ & .98 \\
\hline $\begin{array}{l}\text { Chambless et al., } \\
1998\end{array}$ & 631 & $\begin{array}{l}\text { Gibbs \& Gambrill, } \\
1999\end{array}$ & .98 \\
\hline $\begin{array}{l}\text { Howard, McMillen, } \\
\& \text { Pollio, } 2003\end{array}$ & 627 & CSWE, 2008 & .97 \\
\hline \multicolumn{4}{|c|}{ Ten Most Central Publications in German-Speaking Countries } \\
\hline $\begin{array}{l}\text { McNeece \& Thyer, } \\
2004\end{array}$ & 638 & Sackett et al., 1996 & 1.00 \\
\hline Sackett et al., 1996 & 565 & Gambrill, 2001 & .91 \\
\hline Dewe \& Otto, 2012 & 455 & $\begin{array}{l}\text { Pawson \& Tilley, } \\
1997\end{array}$ & .89 \\
\hline Gambrill, 2001 & 441 & Dewe \& Otto, 2012 & .87 \\
\hline Webb, 2001 & 425 & Kindler, 2005 & .85 \\
\hline $\begin{array}{l}\text { Pawson \& Tilley, } \\
1997\end{array}$ & 387 & Webb, 2001 & .81 \\
\hline Gambrill, 1999 & 379 & Ziegler, 2003 & .81 \\
\hline Kindler, 2005 & 334 & $\begin{array}{l}\text { McNeece \& Thyer, } \\
2004\end{array}$ & .80 \\
\hline Oevermann, 1996 & 309 & Oevermann, 1996 & .79 \\
\hline Schmidt, 2006 & 306 & Grove et al., 2000 & .78 \\
\hline
\end{tabular}


Figure 1. Flow diagram of inclusion and exclusion process.

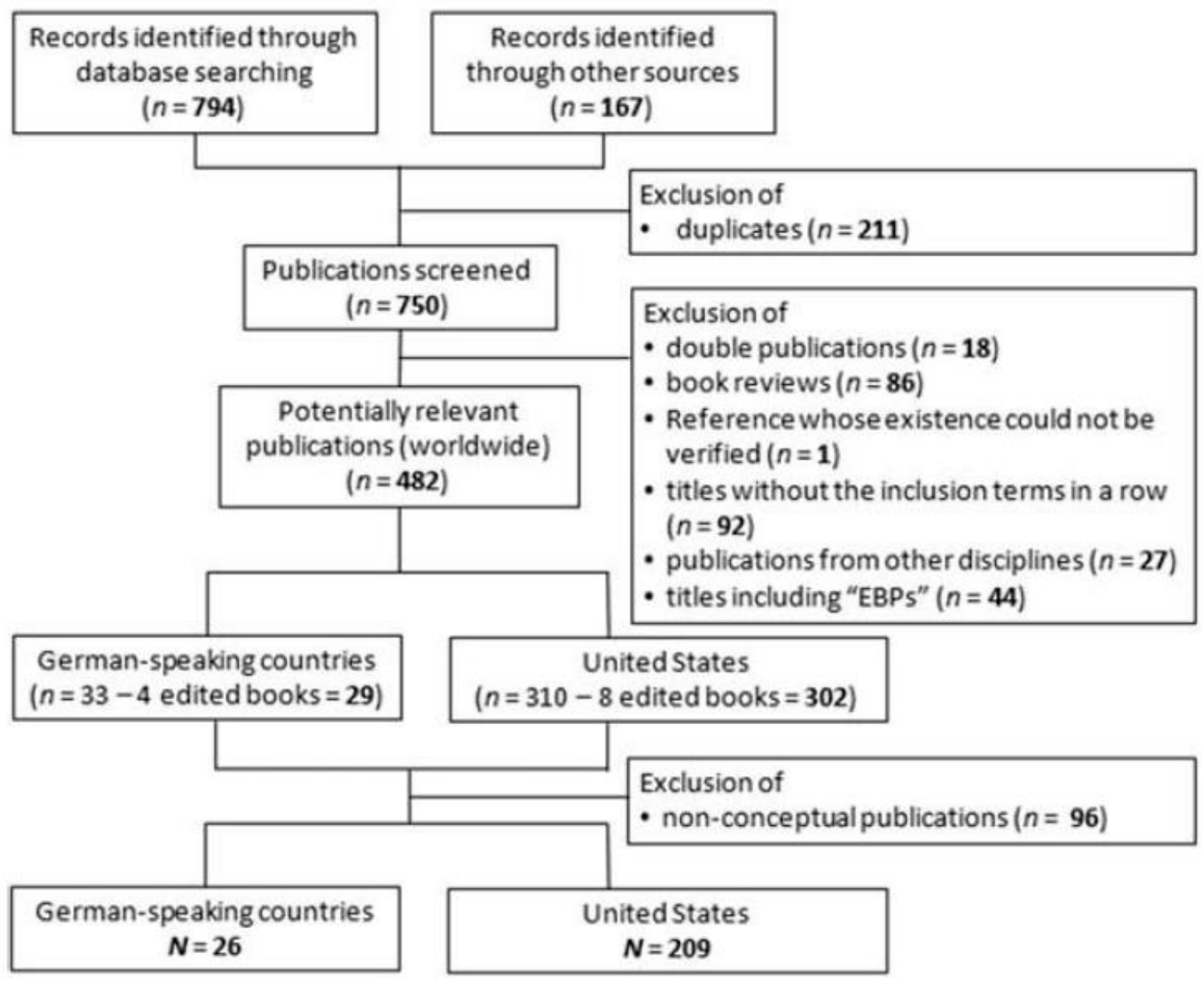


Figure 2. Number of publications per year in the United States and in German-speaking countries.

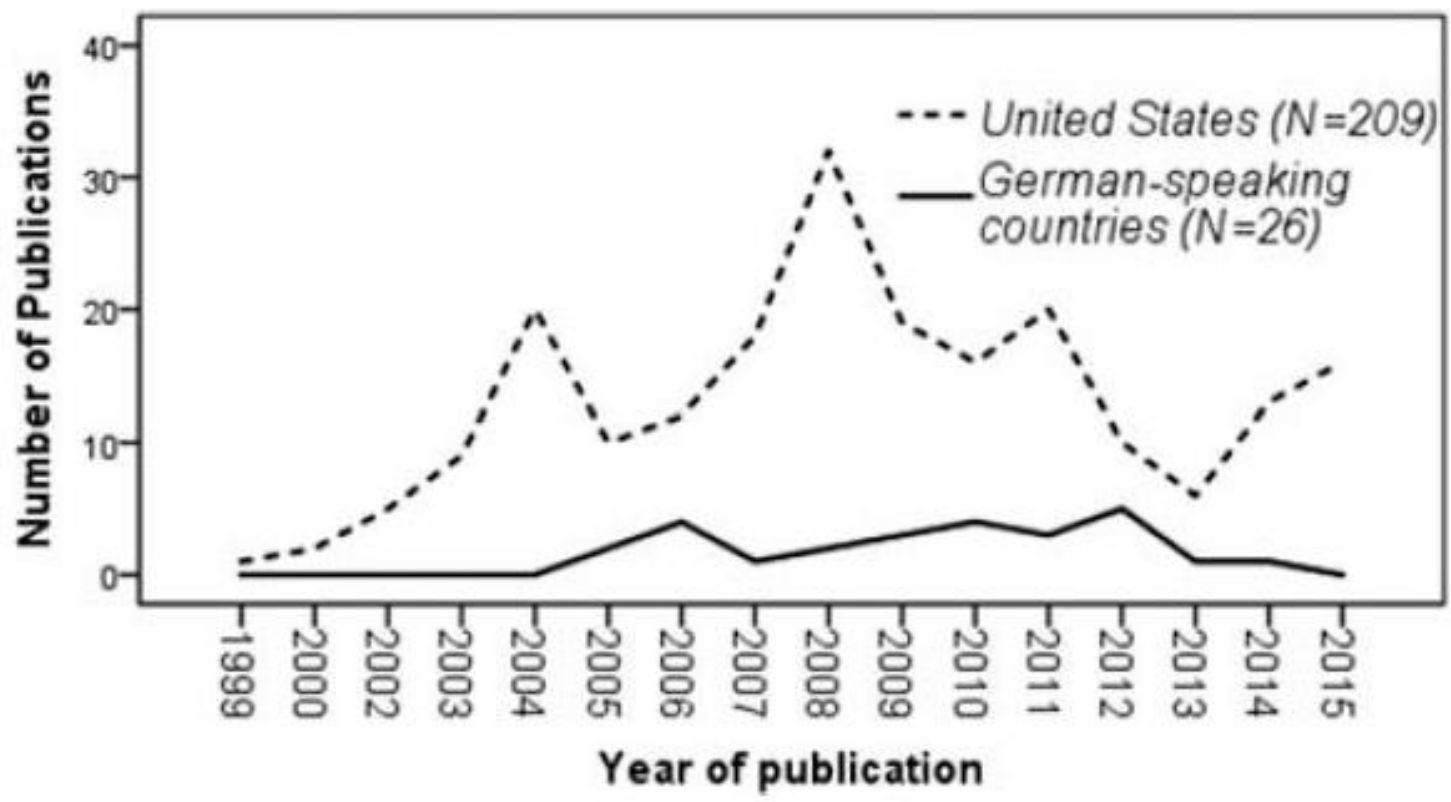


Figure 3. Co-citation network (no. of nodes $=1,389$, no. of edges $=126,092$ ) of the EBP discourse in the United States (right) and the most central publications within this network (left).
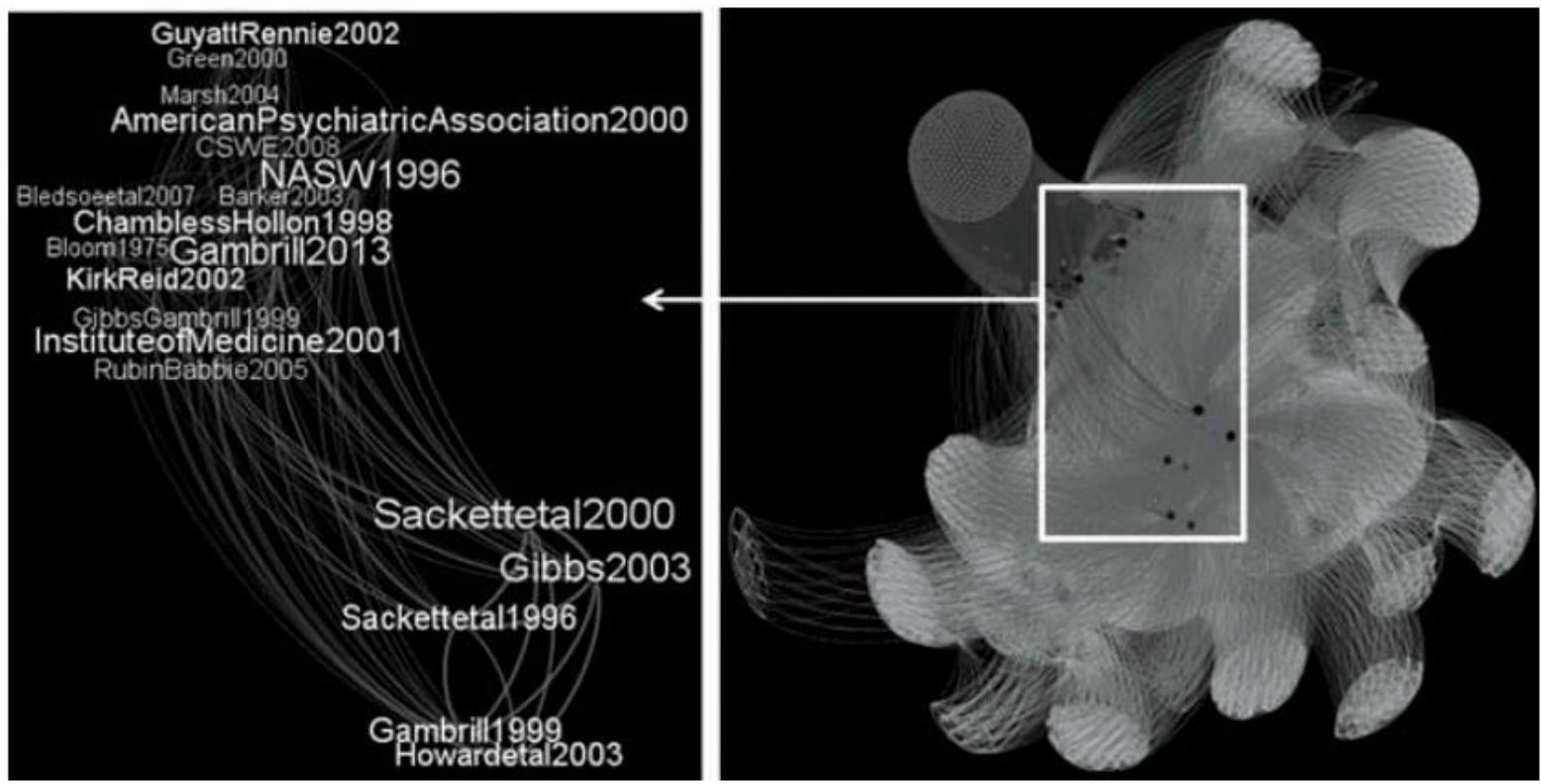
Figure 4. Co-citation network (no. of nodes $=833$, no. of edges $=33,442$ ) of the EBP discourse in German-speaking countries (right) and the most central publications within this network (left).
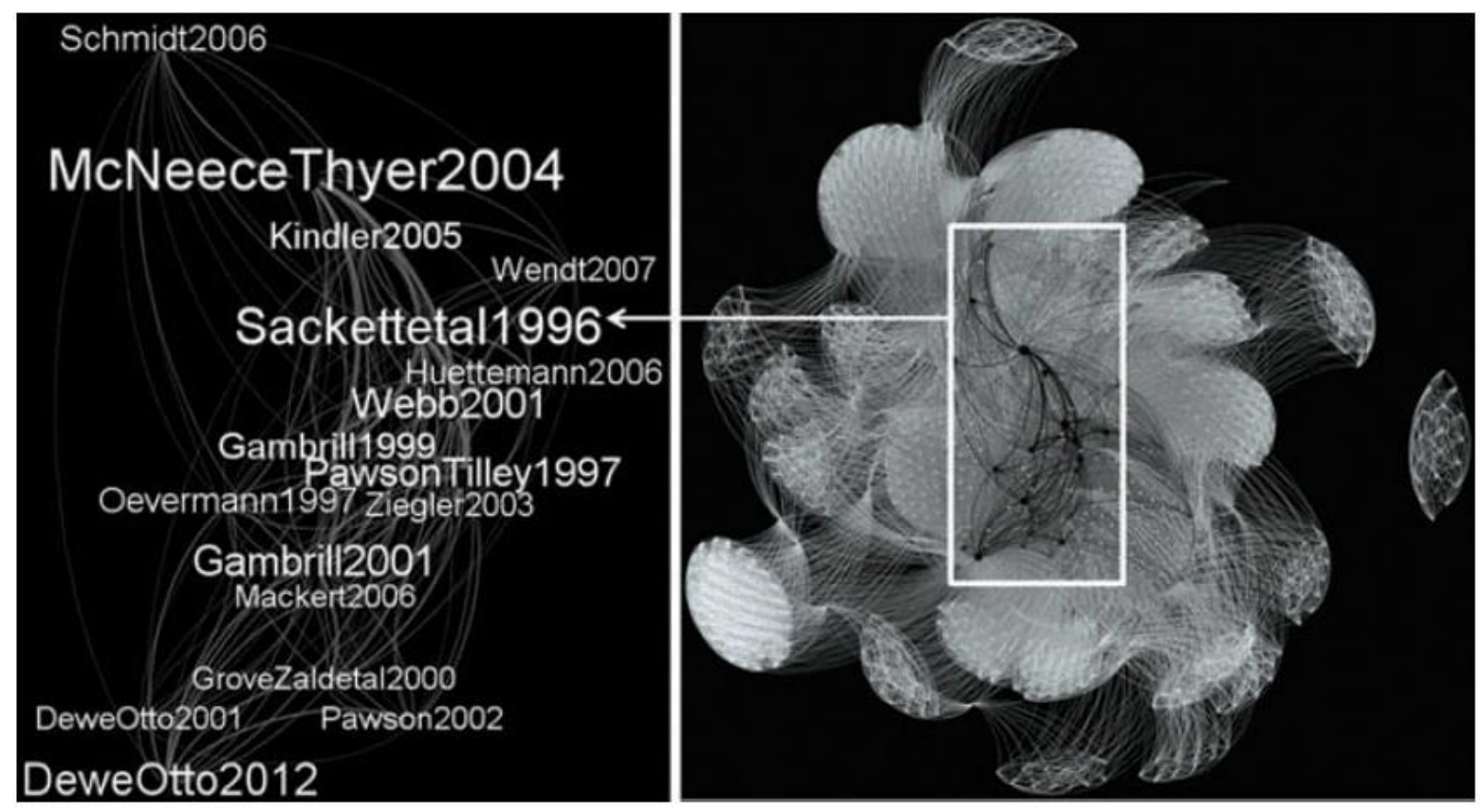